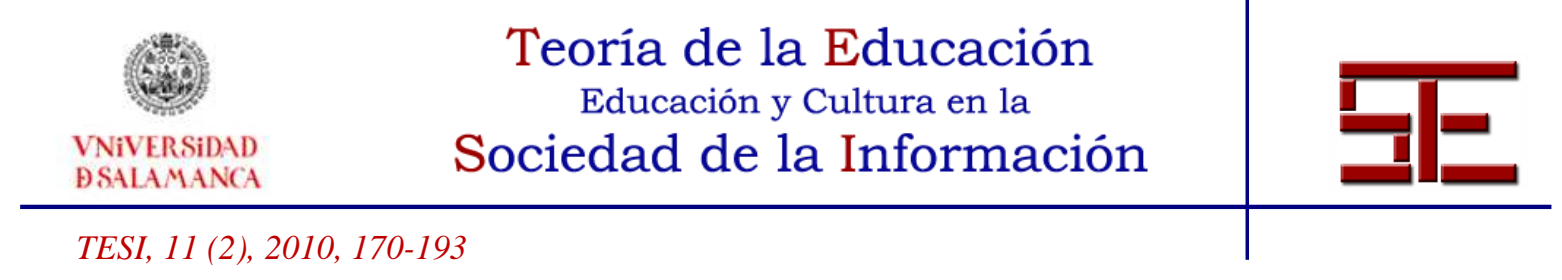

\title{
VIX: UNA APLICACIÓN INFORMÁTICA ABIERTA PARA LA VISUALIZACIÓN Y ESTUDIO INTERACTIVO DE LA ANATOMÍA EN 3D
}

\section{Resumen:}

En el presente trabajo se describen las características funcionales y aplicaciones en el campo de la anatomía de un software de visualización 3D denominado ViX, acrónimo de Visor de directX. Se trata de una aplicación abierta, es decir, no limitada a la representación de una región anatómica determinada. Puede ser configurada externamente, a través de la modificación de ficheros de texto que definen los elementos que componen la escena gráfica. Consta de un visor 3D, desarrollado en visual $\mathrm{C}, \mathrm{y}$ soporta dos tipos de elementos gráficos: (1) visualización simultánea de imágenes en los tres planos ortogonales del espacio; y (2) modelos sólidos de superficie definidos mediante mallas poligonales de triángulos, corregistrados con las imágenes. Los modelos pueden tener asociada una breve descripción que se muestra en una ventana de texto. La funcionalidad de la aplicación se ha ensayado en diferentes regiones topográficas y sistemas funcionales.

Palabras Clave:Anatomía virtual; modelización geométrica; visualización 3D; software educativo; formación médica.

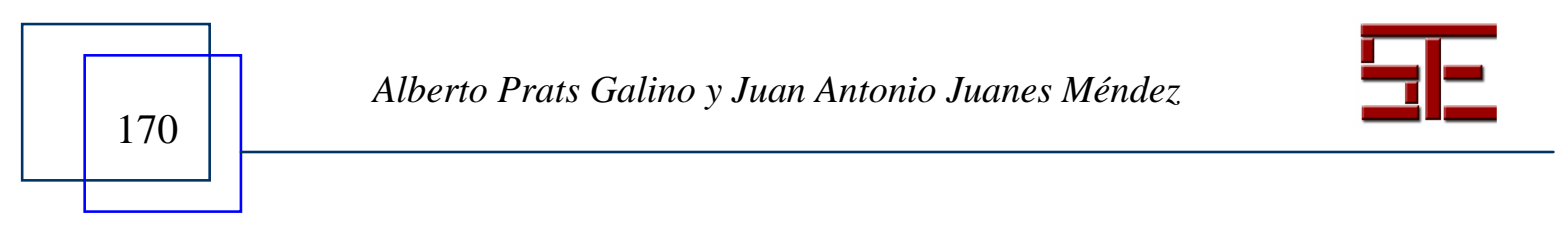




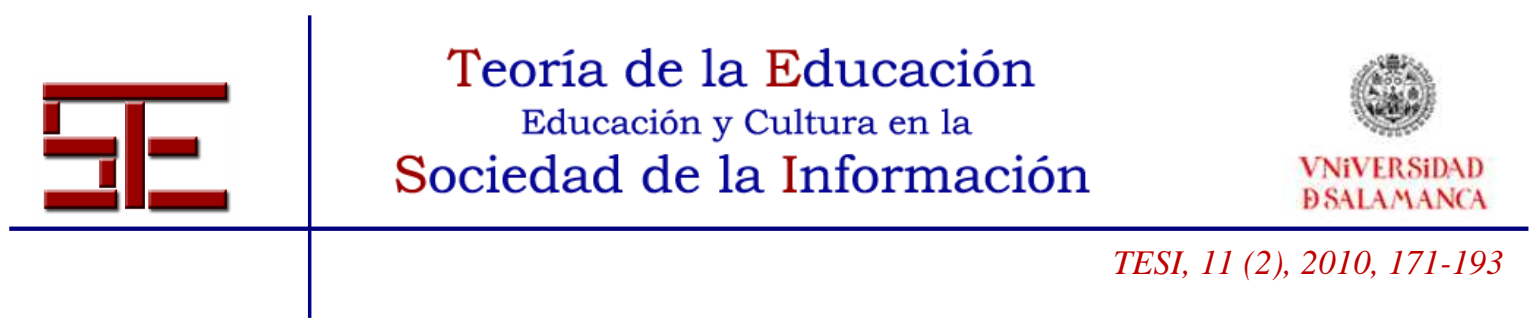

\section{VIX: AN OPEN SOFTWARE FOR THE 3D VISUALIZATION AND INTERACTIVE STUDY OF ANATOMY}

Summary:

This paper describes the functional characteristics and applications in the field of anatomy of a 3D visualization software called ViX, short for directX viewer. This is an open software, ie not limited to the representation of a particular anatomical region.

It can be configured externally through the modification of text files that define the elements composing the scene graph. It consists of a 3D viewer, developed in Visual C, and supports two types of graphic elements: (1) simultaneous display of images in the three orthogonal planes of space, and (2) surface solid models defined by polygon meshes of triangles, coregistered with the images. Models can be associated with a short description that is displayed in a text window. The functionality of the software has been tested in different topographic regions and functional systems.

Key Words:Virtual anatomy; geometric modelling; 3D visualization; educational software; medical education.

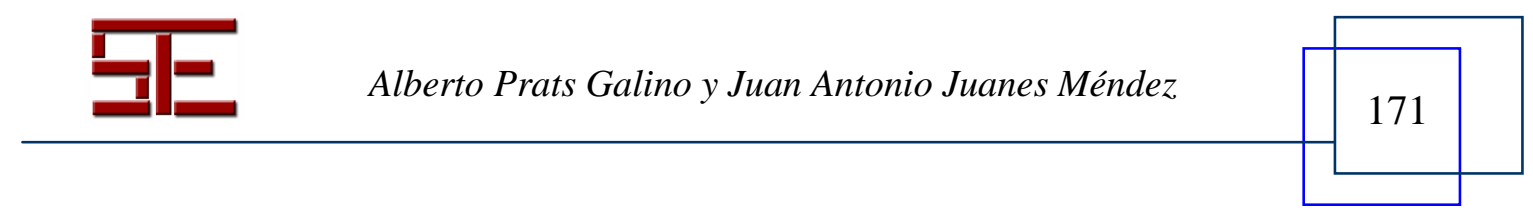




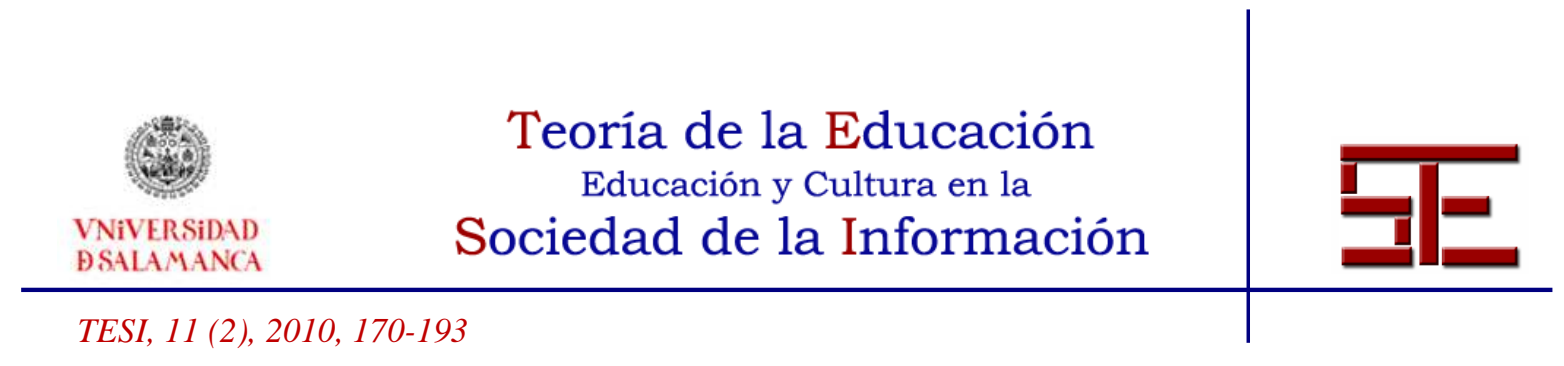

\title{
VIX: UNA APLICACIÓN INFORMÁTICA ABIERTA PARA LA VISUALIZACIÓN Y ESTUDIO INTERACTIVO DE LA ANATOMÍA EN 3D
}

Fecha de recepción: 19/12/2009; fecha de aceptación: 16/04/2010; fecha de publicación: 05/07/2010

\author{
Alberto Prats Galino \\ aprats@ub.edu \\ Universidad de Barcelona \\ Juan Antonio Juanes Méndez \\ jajm@usal.es \\ Universidad de Salamanca
}

\section{1.- INTRODUCCIÓN}

Las nuevas estrategias docentes aplicadas a la Medicina, y concretamente a la adquisición de competencias con las que se relaciona la Anatomía Humana en el contexto del Espacio Europeo de Educación Superior, están encaminadas a promover un aprendizaje dinámico y activo con el objetivo de formar buenos profesionales. En este proceso de aprendizaje no sólo está contemplada la adquisición de contenidos, sino también de habilidades y actitudes (ANECA, 2005). Por ello, no es de extrañar que exista un interés creciente por la incorporación de sistemas informáticos que amplien la oferta formativa basada en nuevas tecnologías que contemplen estos aspectos.

En este sentido, en los últimos años se han introducido diferentes aplicaciones multimedia para el estudio interactivo de la Anatomía, de gran utilidad para programar actividades formativas basadas en el autoaprendizaje con soportes informáticos. Especificamente se han desarrollado programas que facilitan el examen de la anatomía seccional, el uso de modelos sintéticos 3D con vistas predefinidas (Prats y Juanes, 2007), y el análisis de la morfología y anatomía funcional con escenas 3D QuickTime VR prediseñadas que pueden explorarse interactivamente. (Carmichael y Pawlina, 2000; Elizondo-Omaña et al, 2004). No obstante, la mayoría de estos programas son cerrados,

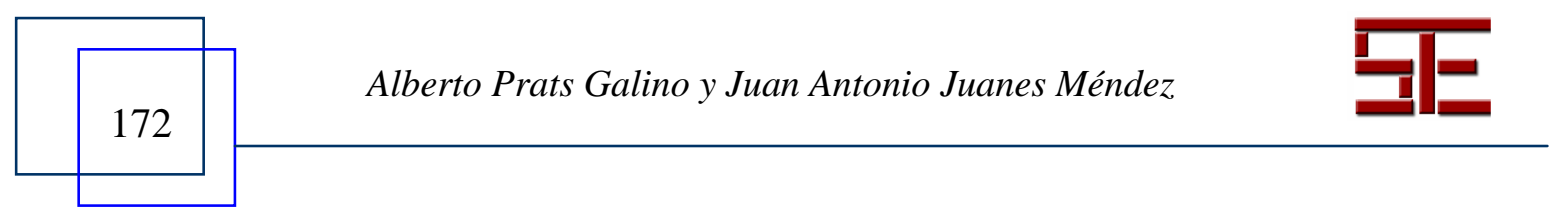




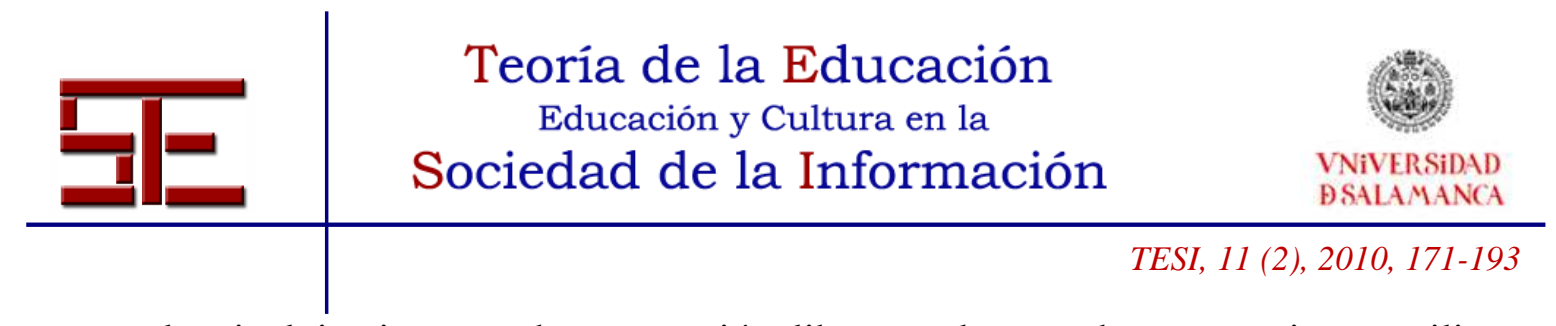

no suelen incluir sistemas de navegación libre, y algunas de sus versiones utilizan complejas técnicas de rendering que precisan potentes estaciones gráficas y dificultan la práctica de sesiones en tiempo real.

Este tipo de tecnologías aplicadas a la docencia posibilitan la observación de la Anatomía Humana desde distintos puntos de vista, lo que facilita una mejor comprensión e identificación de las estructuras anatómicas que constituyen el cuerpo humano, favoreciendo un mejor aprendizaje.

En el presente trabajo se describen las características funcionales y aplicaciones, en el campo de la Anatomía, de un software de visualización 3D denominado ViX, acrónimo de Visor de directX. Se trata de una aplicación abierta, es decir, no limitada a la representación de una determinada región anatómica o sistema funcional, ya que puede ser configurada externamente a través de la modificación de ficheros de texto que definen los elementos que componen la escena gráfica. Así mismo, se describen algunos de los entornos gráficos en lo que ha sido empleada.

\section{2.- METODOLOGÍA Y RESULTADOS}

ViX es una aplicación de visualización para entornos Windows, programada en Visual $\mathrm{C}$, que incluye controles ActiveX. Está diseñada para optimizar las capacidades de aceleración gráfica que soportan las tarjetas actuales. Permite representar dos tipos de elementos gráficos:

(1) visualización simultánea de imágenes en los tres planos ortogonales del espacio: axial, coronal y sagital; y

(2) modelos sólidos de superficie definidos mediante mallas poligonales de triángulos, corregistrados con las imágenes. Los modelos pueden tener asociados una breve descripción que se muestra en una ventana de texto.

Se describen sucesivamente los componentes y funciones de la interfaz gráfica, el procedimiento general para la obtención tanto de imágenes como de modelos 3D y la definición de escenas gráficas para su visualización en ViX, incluyéndose por último una referencia a diferentes aplicaciones que han sido implementadas en este entorno gráfico

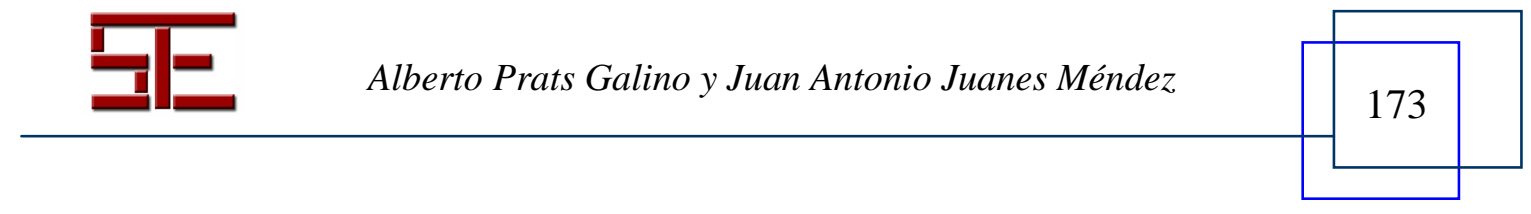




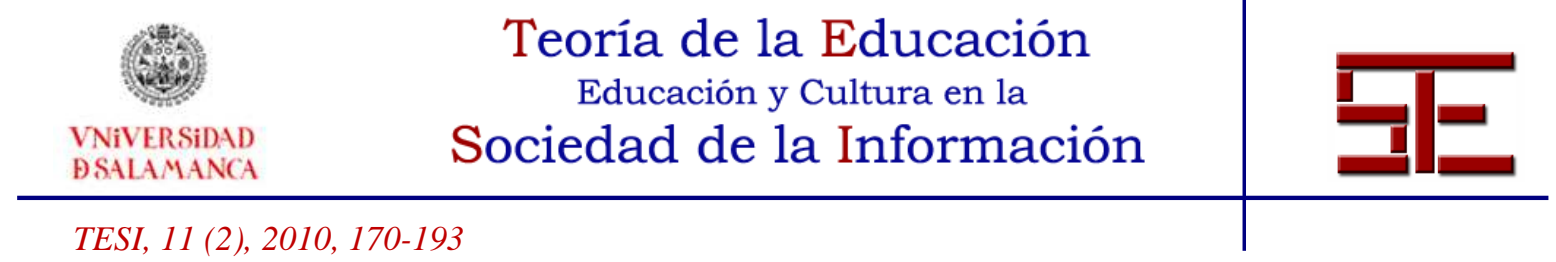

\section{1.- Interfaz gráfica}

La interfaz gráfica de ViX es de manejo muy sencillo e intuitivo y consta básicamente de 3 áreas: selector de escenas, visor $3 D$ y área de controles (Fig 1).

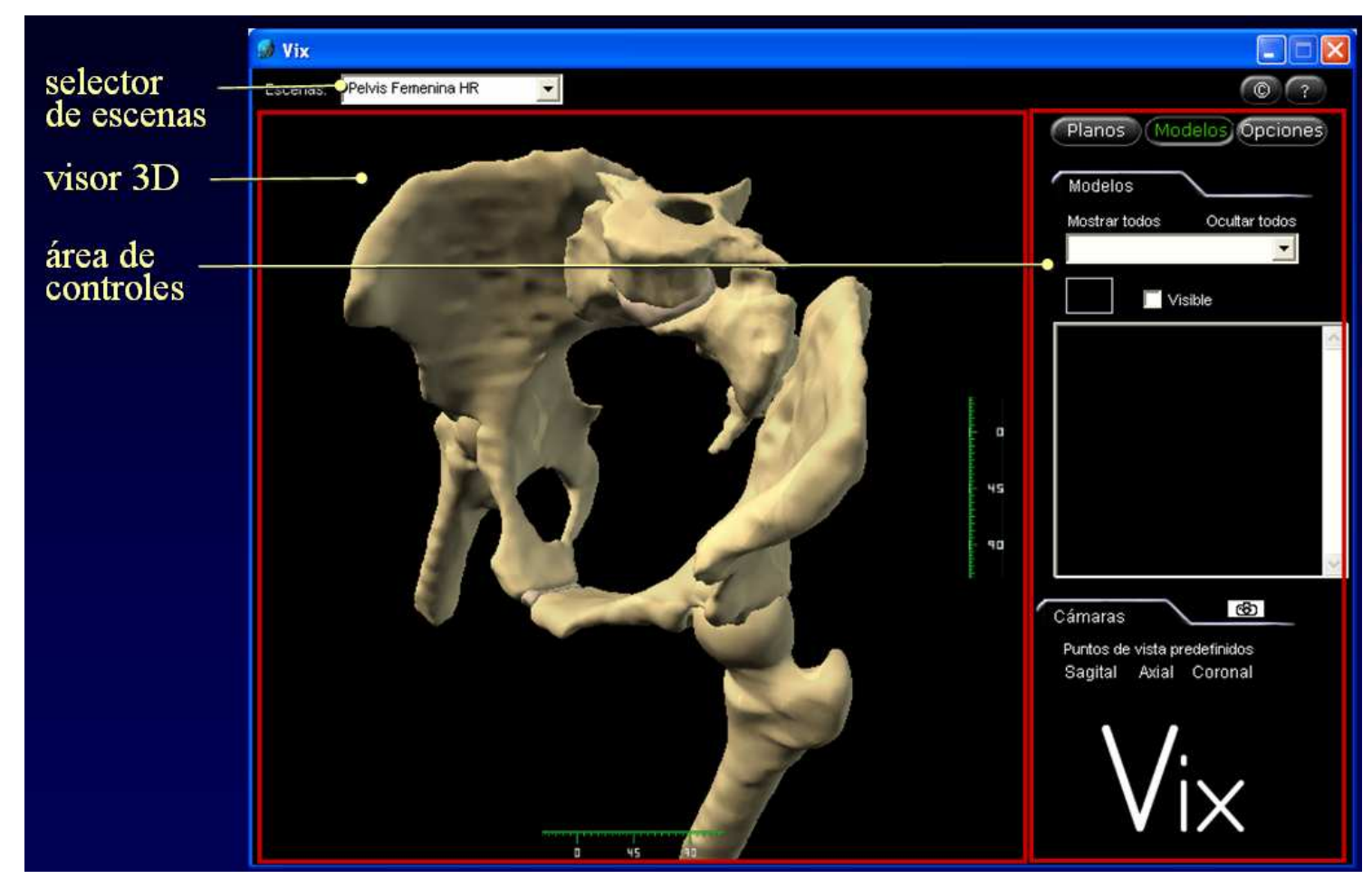

Fig. 1. Principales componentes de la interfaz gráfica de ViX: selector de escenas, visor 3D y área de

\section{2.- Selector de escenas}

controles

Es un control de tipo lista desplegable, a través del que puede seleccionarse una de las escenas anatómicas predefinidas en un fichero de texto, que el programa lee en el momento de su ejecución. Este fichero puede contener un número variable de escenas, que se definen de acuerdo con la siguiente sintaxis:
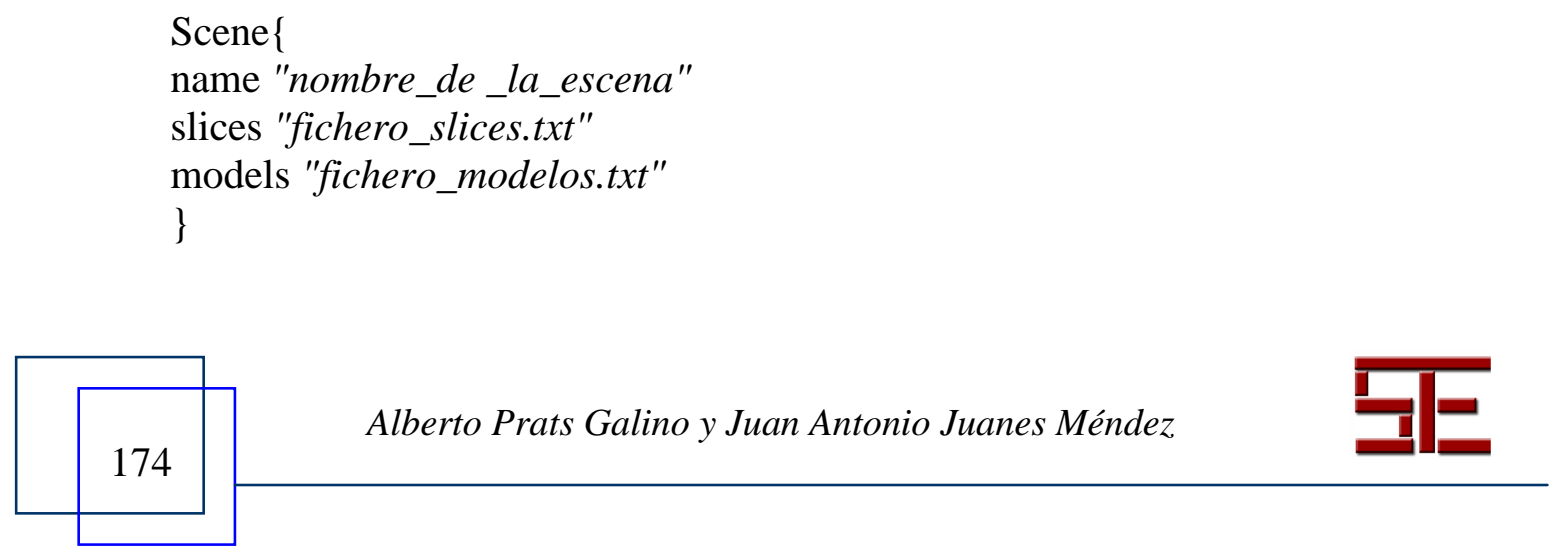


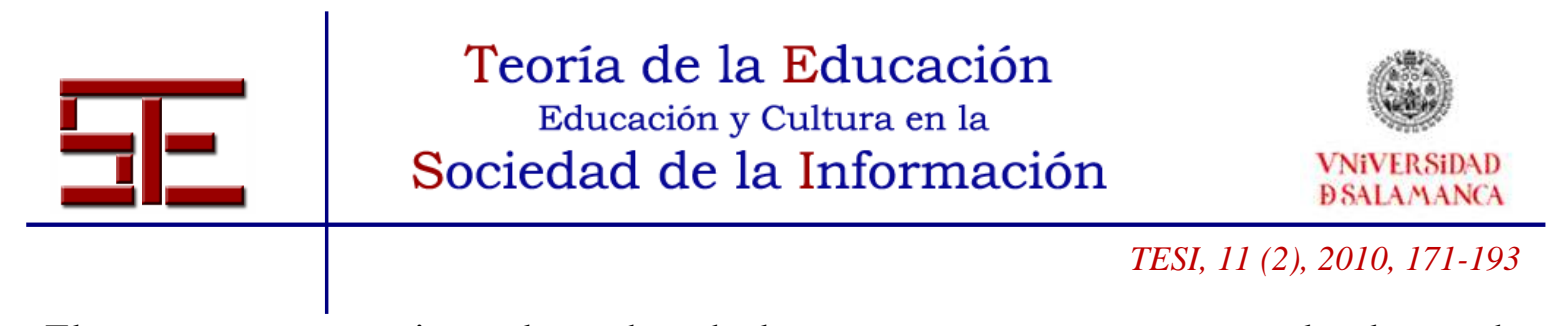

El campo name contiene el nombre de la escena que se muestra en el selector de escenas, mientras que los campos slices y models se emplean para indicar, respectivamente, el nombre del fichero de definición de las características de las imágenes y de los modelos que forman parte de la escena, como se describe más adelante.

\section{3.- Visor $3 D$}

Ocupa la mayor parte de la interfaz gráfica, y se encuentra situado en su parte izquierda (Fig 1).

En el visor se representan los diferentes elementos que constituyen la escena. Permite la interacción directa con estos elementos gráficos mediante el ratón. Entre sus propiedades se encuentran:

- rotación libre de la escena

Se obtiene presionando el botón principal del ratón, generalmente el izquierdo, y desplazando el cursor sobre el visor.

- zoom de la escena

Se obtiene mediante el botón secundario del ratón, generalmente el derecho. Su desplazamiento hacia arriba produce un efecto de ampliación, obteniéndose el efecto contrario cuando el cursor se desplaza hacia abajo.

- traslación de la escena (pan)

Puede trasladarse la escena horizontal y verticalmente manteniendo ambos botones del ratón presionados simultáneamente, mientras se desplaza el cursor sobre el visor.

- selección de modelos

Para seleccionar un modelo se sitúa el cursor en su vecindad, haciéndose clic con el botón principal. El modelo seleccionado es iluminado y a su alrededor se muestra su cuadro delimitador, con el color del propio modelo (bounding box).

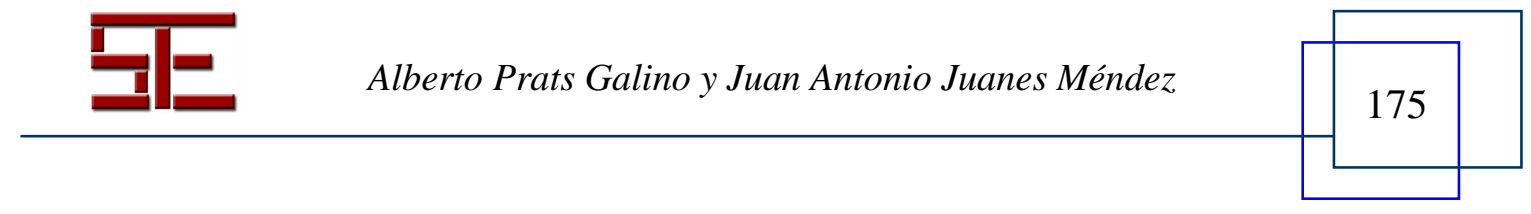




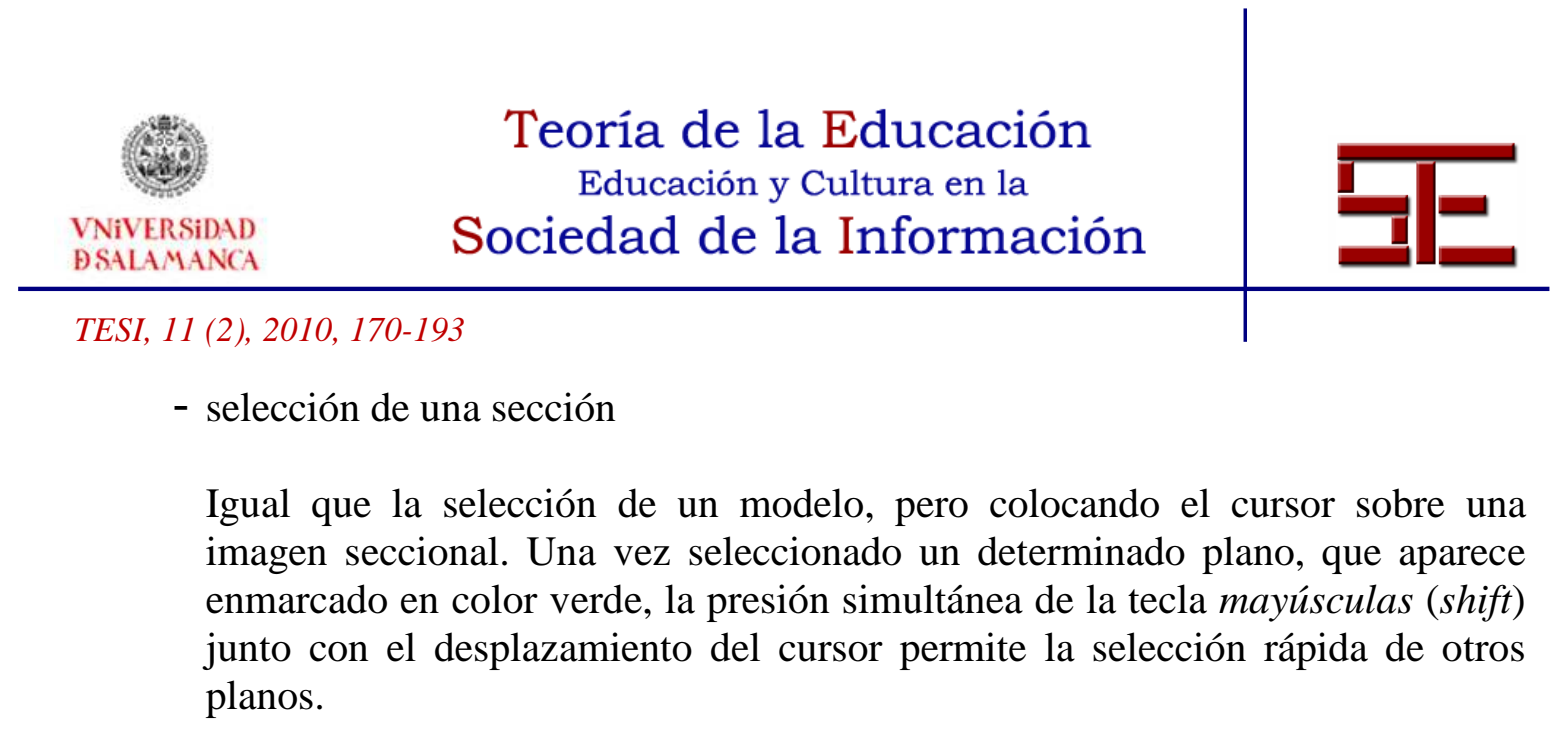

\section{4.- Área de controles}

Es un área vertical localizada en la parte derecha de la aplicación (Fig. 1). Está formada por dos sectores, uno superior, con los botones Planos, Modelos y Opciones, y uno inferior, identificado con la etiqueta Cámaras.

\subsection{1.- Botón de Planos}

Con el botón de Planos se accede a los controles de los planos (Fig. 2). Existen 3 planos de orientación: sagital, axial (horizontal) y coronal (frontal).

Cada plano dispone de una caja de selección de visualización, una barra de desplazamiento (slicer) para la selección del nivel de corte, así como una caja de selección de visualización de rejilla, cuyo tamaño puede modificarse mediante una lista numérica desplegable.

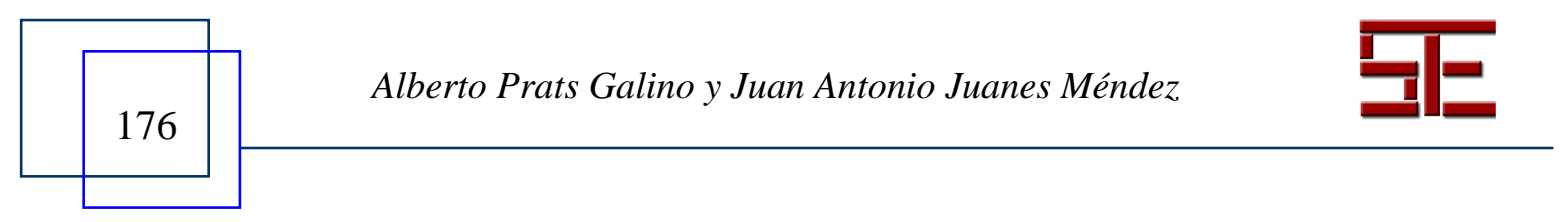




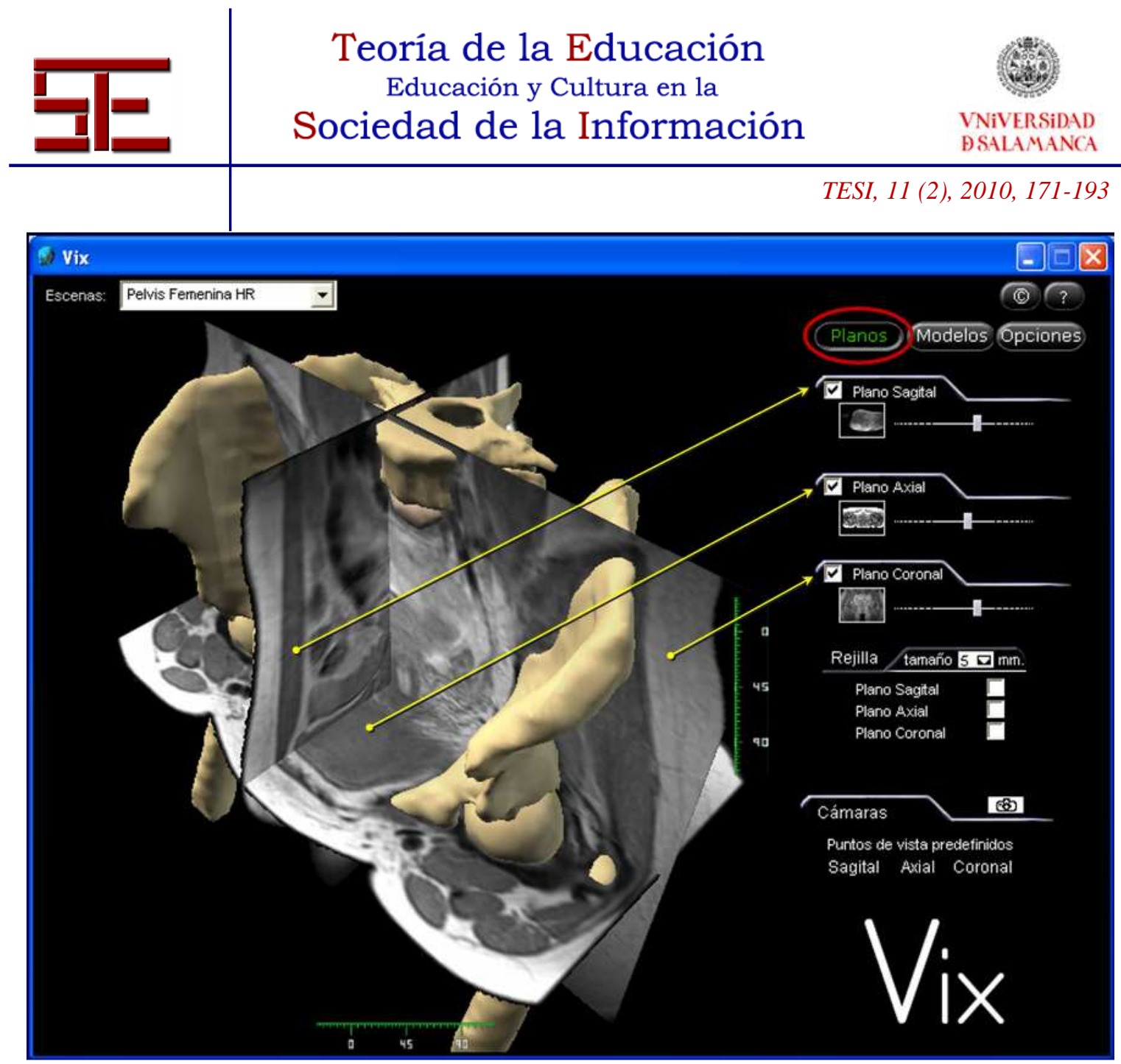

Fig. 2. Controles asociados al botón Planos. Para cada orientación -Sagital, Axial y Coronal-existe una caja de visualización, un slicer que permite seleccionar la sección a visualizar, y una rejilla de dimensiones regulables.

\subsection{2.- Botón de Modelos}

Con el botón de Modelos se accede a los controles de los modelos 3D (Fig. 3). Dichos controles constan de una lista desplegable, para la selección del modelo a representar. Cada modelo seleccionado tiene asociado una caja de selección de visualización, un control de selección de color y, en la parte inferior, un cuadro de texto que muestra una breve descripción del mismo. Los botones Mostrar todos y Ocultar todos se emplean, respectivamente, para mostrar u ocultar todos los modelos de la escena.

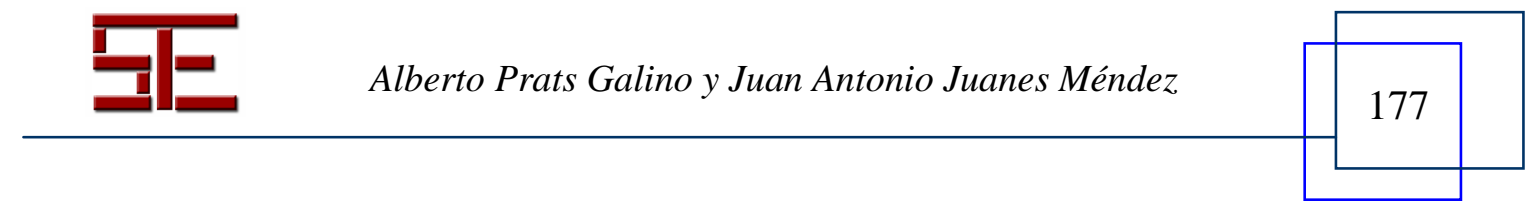




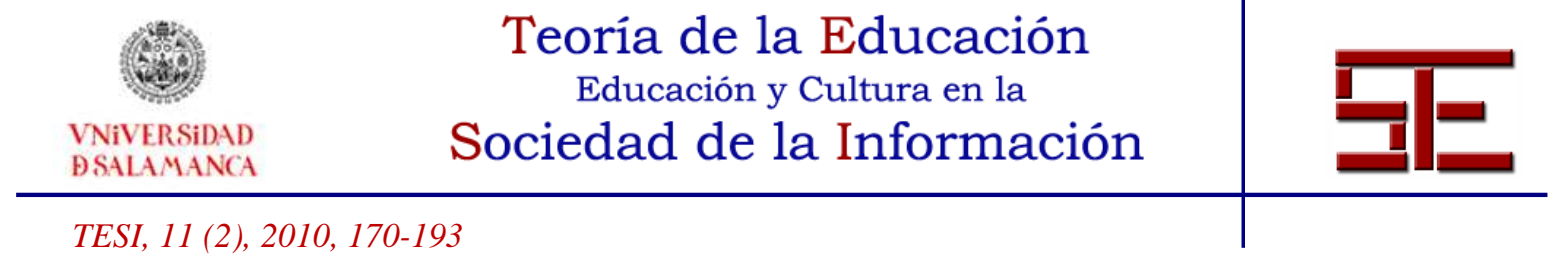

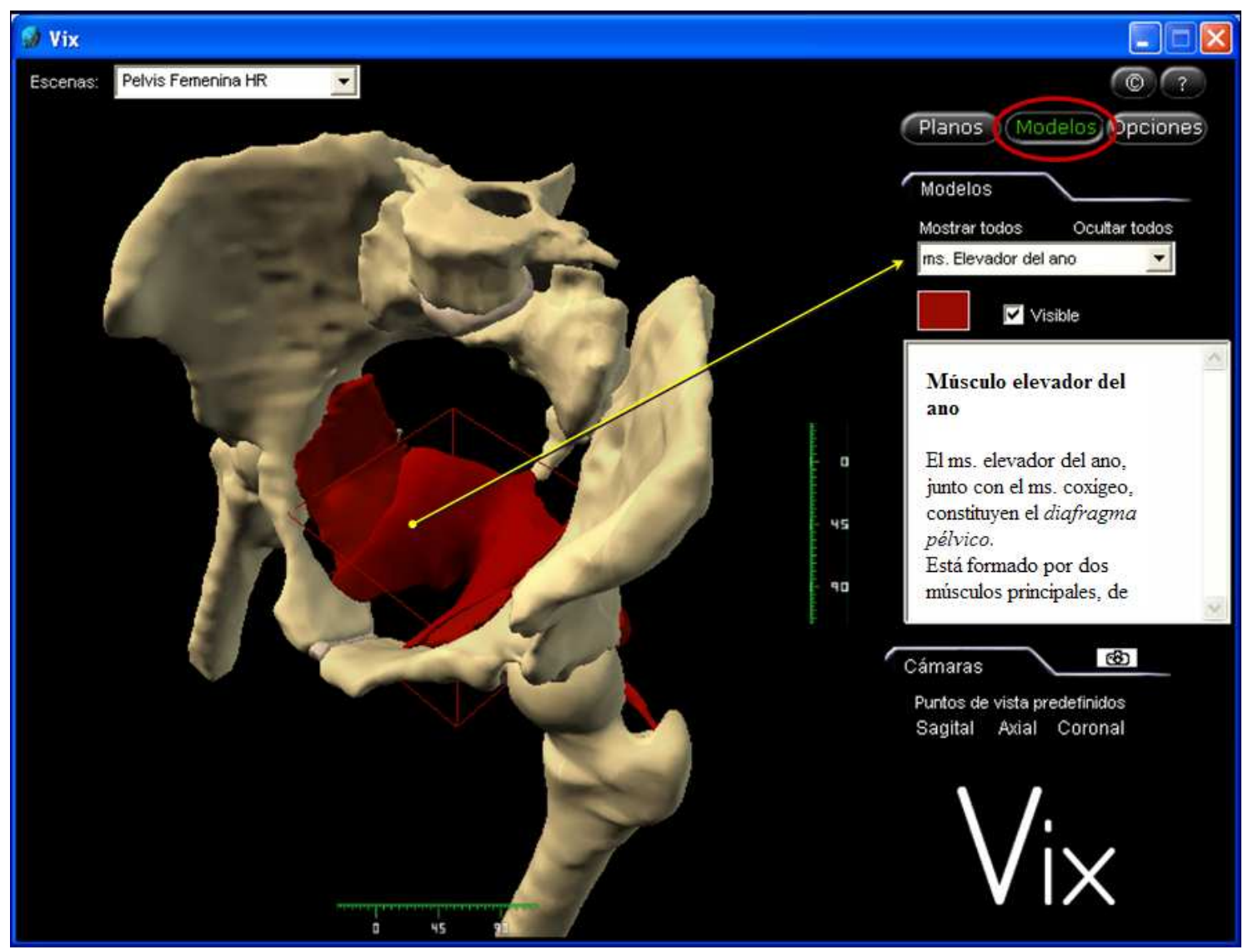

Fig. 3. Controles asociados al botón Modelos. Para cada modelo seleccionado a través de una lista desplegable se muestra una caja de selección de color, con su color actual, su estado de visibilidad y el texto descriptivo asociado.

\subsection{3.- Botón Opciones}

El botón Opciones da acceso a funciones que modifican las características o el comportamiento general del Visor $3 D$, como son el control del color de fondo, de los marcos de imágenes y de la rejilla, cajas de selección para la restricción de rotaciones en los planos horizontal y vertical, y un botón que inicializa la escena, cargándola nuevamente.

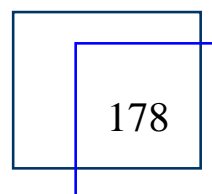

Alberto Prats Galino y Juan Antonio Juanes Méndez

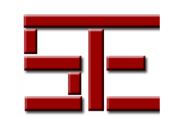




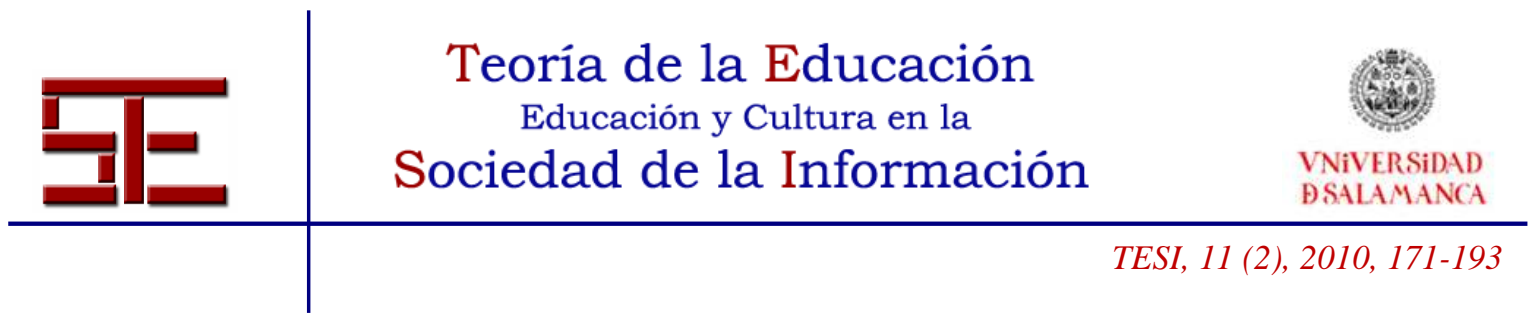

\subsection{4.- Controles de Cámaras}

Localizados en la parte inferior del Área de controles (Fig. 3), permiten la aplicación de 3 vistas predefinidas: lateral (Sagital), superior (Axial), y anterior (Coronal) (Fig. 4). El icono adyacente de cámara fotográfica permite capturar la imagen del Visor y almacenarla en formato BMP.
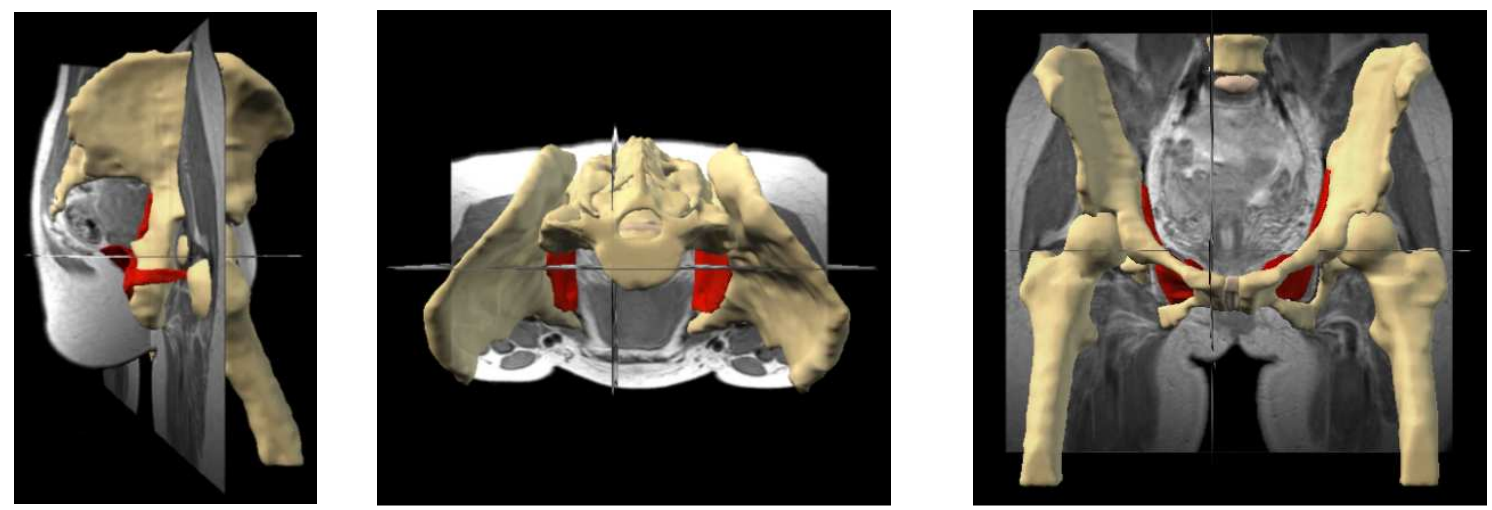

Fig. 4. Vista de cámara predefinidas: lateral (Sagital), superior (Axial) y anterior (Coronal)

\section{3.- OBTENCIÓN Y DEFINICIÓN DE IMÁGENES SECCIONALES}

ViX soporta imágenes en formato PNG. Para la creación de escenas pueden utilizarse imágenes seccionales anatómicas, resonancias magnéticas -RM- (potenciadas en T1, T2, densidad protónica, flash-3D), tomografías computadas -TC-, SPECT (Single Photon Emission Computed Tomography), o cualquier otra modalidad radiológica.

En general la obtención de estas imágenes suele requerir una secuencia de ficheros raw data DICOM (Digital Imaging and Communication in Medicine), de la región topográfica de interés, a partir de la cual se reconstruye un volumen único, preferentemente isotrópico, es decir, con voxels cúbicos. Diferentes programas de libre distribución (MRIco, Nottingham, UK), o comerciales (Amira, Visage Imaging Inc; Analyze, Mayo Clinic; MATLAB, MathWorks) pueden utilizarse tanto para la reconstrucción de dicho volumen como para la exportación de imágenes PNG en cada una de las orientaciones del espacio.

Las imágenes renderizadas en el Visor se encuentran definidas en un fichero de texto independiente para cada escena gráfica (Fig. 5). Este fichero está configurado según la siguiente sintaxis:

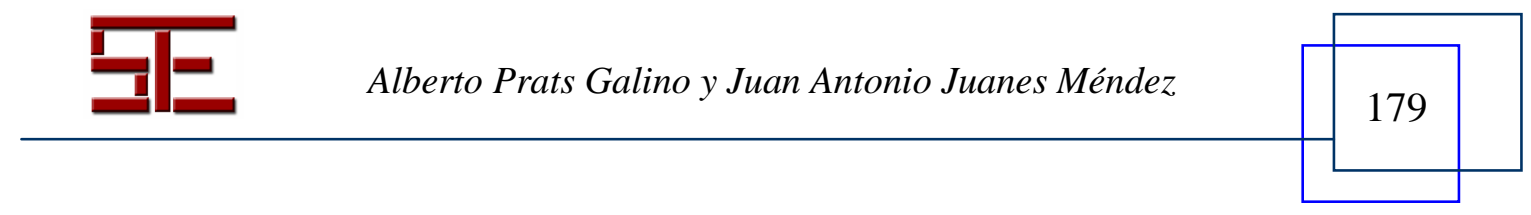




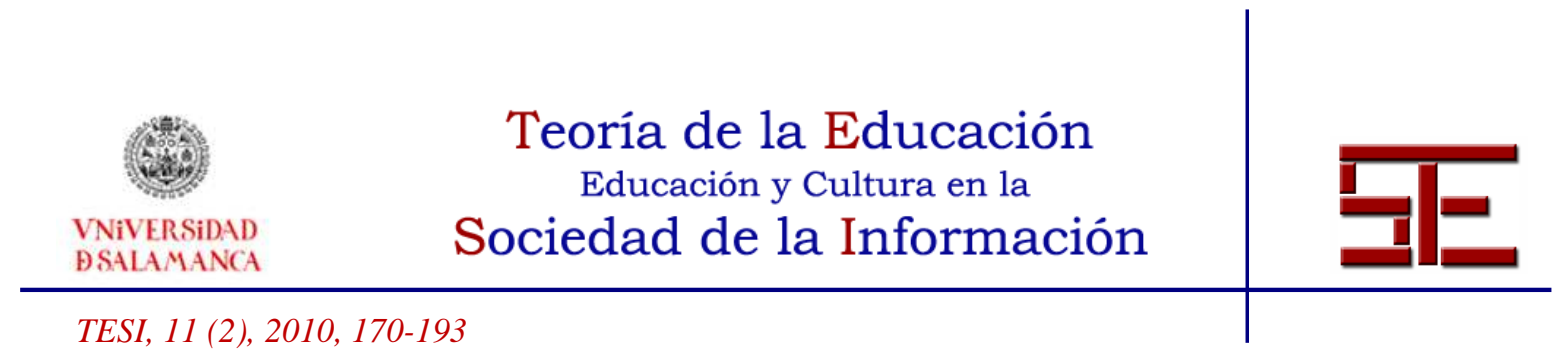

dimension xdim ydim zdim

pixelsize xsize ysize zsize

origin xorigin yorigin zorigin
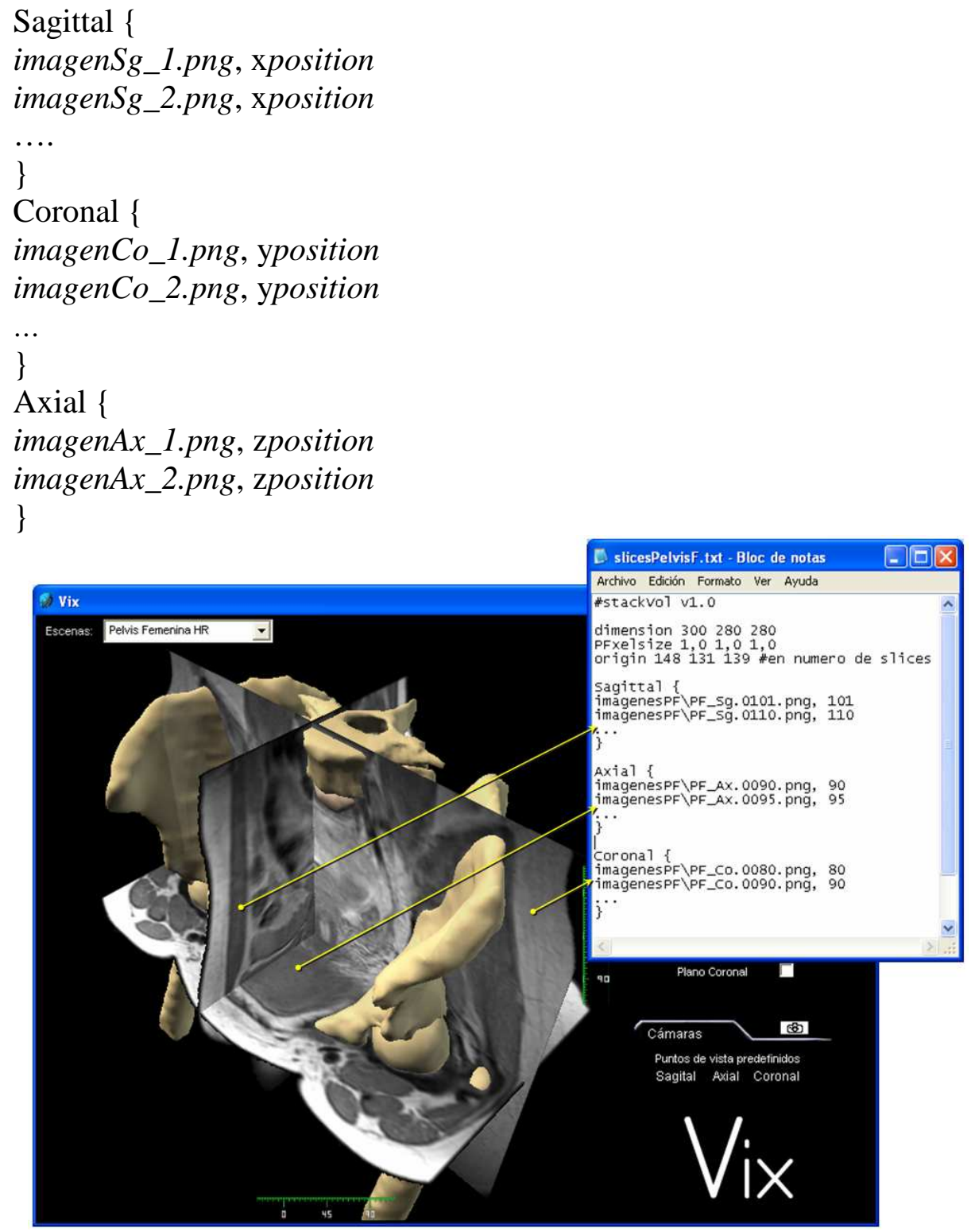

Fig. 5. Ejemplo de fichero de definición de imágenes seccionales, correspondiente a la escena gráfica mostrada en la Fig. 2.

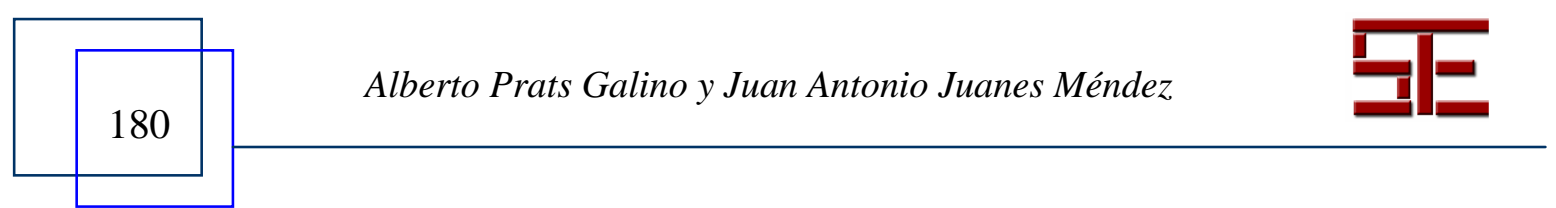




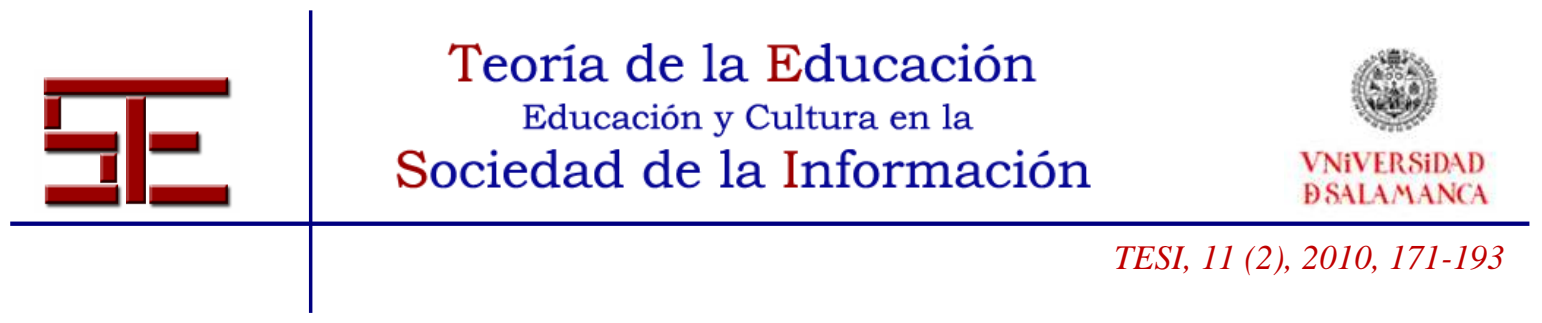

Este fichero contiene la información para disponer las imágenes seccionales en su orientación y posición espacial adecuada, que vienen determinadas por los siguientes parámetros:

- dimension $(\mathrm{x}, \mathrm{y}, \mathrm{z})$ : indica la dimensión total del volumen original del que proceden las imágenes, es decir, el número total de secciones o slices).

- pixelsize (x, y, z): tamaño del voxel, en cada dirección espacial, expresado en milímetros.

- origin $(\mathrm{x}, \mathrm{y}, \mathrm{z})$ : origen -centro de referencia- del volumen.

- orientación: puede ser sagital, coronal o axial.

- nombre del fichero de imagen, seguido de su posición, expresado en número de slice.

\section{4.- OBTENCIÓN Y DEFINICIÓN DE MODELOS TRIDIMENSIONALES (3D)}

La generación de los modelos 3D puede requerir dos tipos de procedimiento, de acuerdo con el tipo de estructura anatómica a reconstruir. Éstos incluyen: (1) reconstrucción de modelos de superficie a partir de secciones seriadas de cualquier modalidad, como son RM, TC o cortes anatómicos; (2) reconstrucción de estructuras de tipo filiformes, como es el caso de la representación de trayectos nerviosos.

\section{1.- Modelos de superficie}

Esta etapa consiste en la identificación de las estructuras anatómicas a reconstruir en las imágenes correspondientes, y su marcaje con diferentes códigos de color, mediante un editor 3D (ej: Amira, Visage Imaging Inc) (Fig. 6). Este tipo de reconstrucción ha sido empleado para obtener modelos de órganos completos, núcleos y vías nerviosas, músculos, huesos, arterias y venas.

A partir de cada una de las regiones de interés (ROIs) resultantes se obtiene un modelo de superficie, compuesto por una malla triangular, mediante un procedimiento de marching cubes (Fig.6). A los modelos triangulares se les aplican opcionalmente algoritmos de decimación para simplificarlos y de suavizado. Finalmente se exportan a formato DirectX (3D Exploration software, Right Hemisphere Inc., Auckland, New Zealand). En algunos casos también se han incorporado modelos generados con aplicaciones de modelado 3D (3D StudioMax, Autodesk)

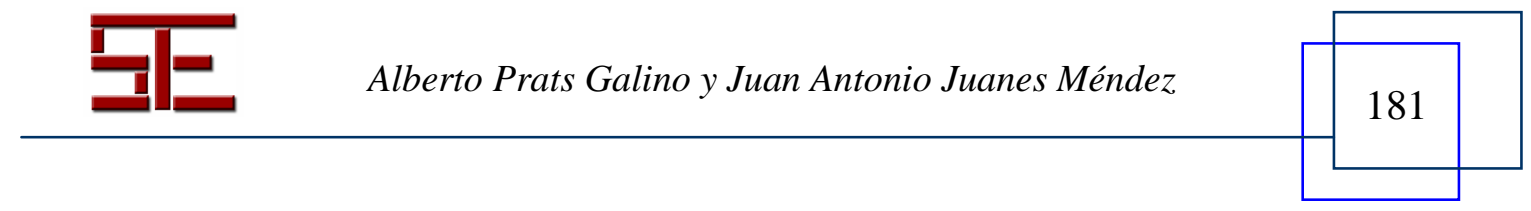




\begin{tabular}{ccc}
$c$ & $\begin{array}{c}\text { Teoría de la Educación } \\
\text { Educación y Cultura en la } \\
\begin{array}{l}\text { VNiVERSIDAD } \\
\text { DSALAMANCA }\end{array}\end{array}$ \\
\hline TESI, $11(2), 2010,170-193$ & Sociedad de la Información & \\
\hline
\end{tabular}
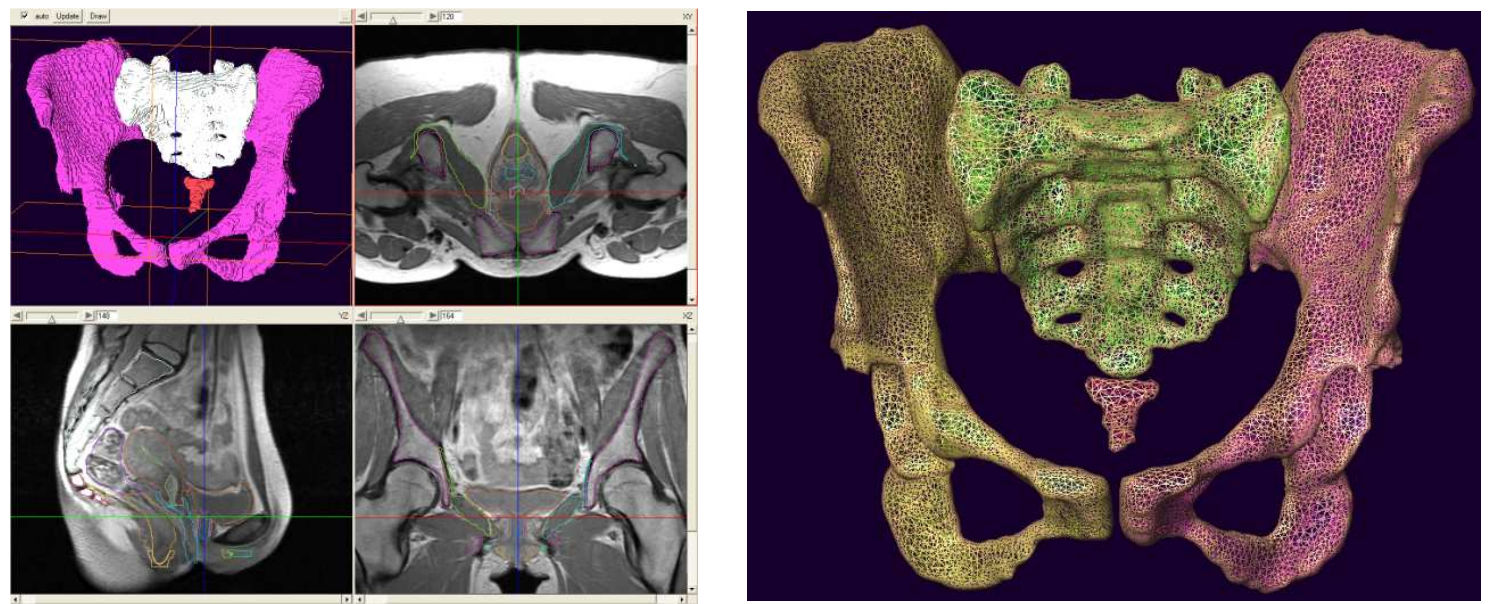

Fig. 6. Delimitación de regiones de interés (ROIs) en un editor 3D sobre imágenes de RM (izquierda), para la obtención de un modelo de malla triangular (derecha).

\section{2.- Estructuras filiformes}

La reconstrucción del trayecto de nervios periféricos, ejes, o líneas de anotaciones, se obtiene trazando polilíneas. Para cada estructura se definen una serie de landmarks a lo largo de su trayecto, basado en el conocimiento anatómico, utilizando referencias reconocibles en las imágenes seccionales (Fig.7). Los diferentes landmarks se unen mediante polilíneas, que se utilizan como base para generar una secuencia de cilindros de pequeño diámetro representando el trayecto reconstruido. Al igual que en los modelos de superficie, cada estructura filiforme se puede representar mediante un modelo independiente en formato DirectX.
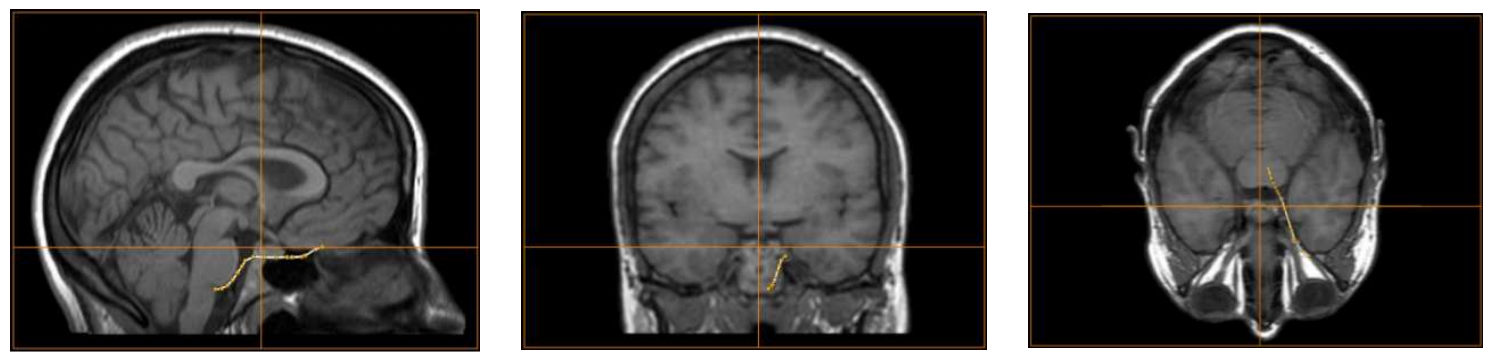

Fig. 7. Reconstrucción del trayecto del nervio oculomotor mediante landmarks que definen una polilínea.

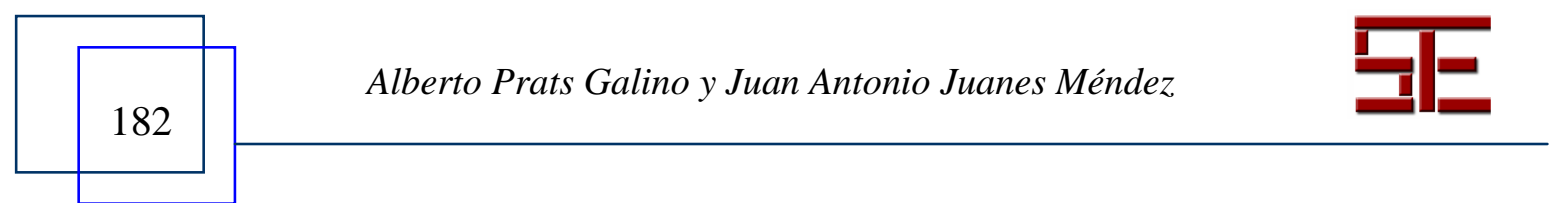




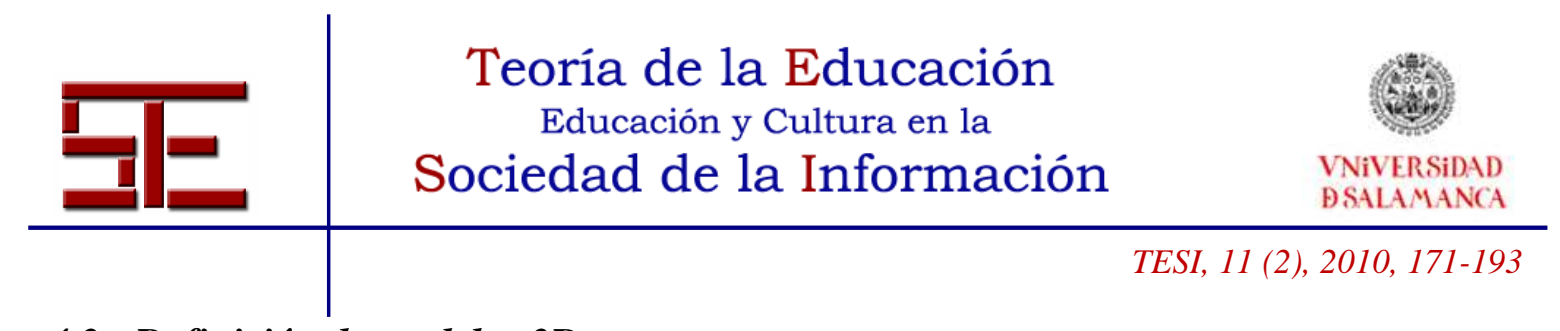

\title{
4.3.- Definición de modelos $3 D$
}

Los modelos 3D se encuentran también definidos, al igual que las imágenes, en un fichero de texto (Fig. 8), que en este caso muestra la siguiente sintaxis:

\author{
Model \{ \\ name "nombre_del_modelo" \\ label "etiqueta_del_modelo" \\ file fichero_de_geometría.x \\ color $r g b$ \\ transparencyRange min max \\ transparency valor \\ drawStyle estilo \\ visible $0 / 1$ \\ documentation fichero_de_documentacion.htm \\ \}
}

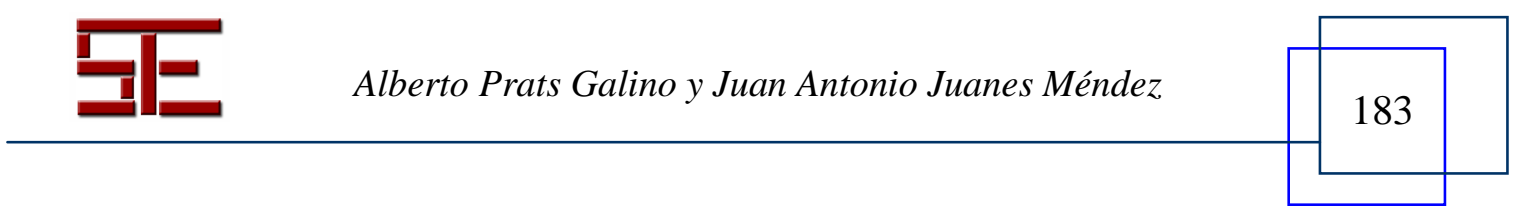




\begin{tabular}{ccc}
$c$ & $\begin{array}{c}\text { Teoría de la Educación } \\
\text { Educación y Cultura en la } \\
\begin{array}{l}\text { VNiVERSIDAD } \\
\text { DSALAMANCA }\end{array}\end{array}$ \\
\hline TESI, $11(2), 2010,170-193$ & Sociedad de la Información & \\
\hline
\end{tabular}

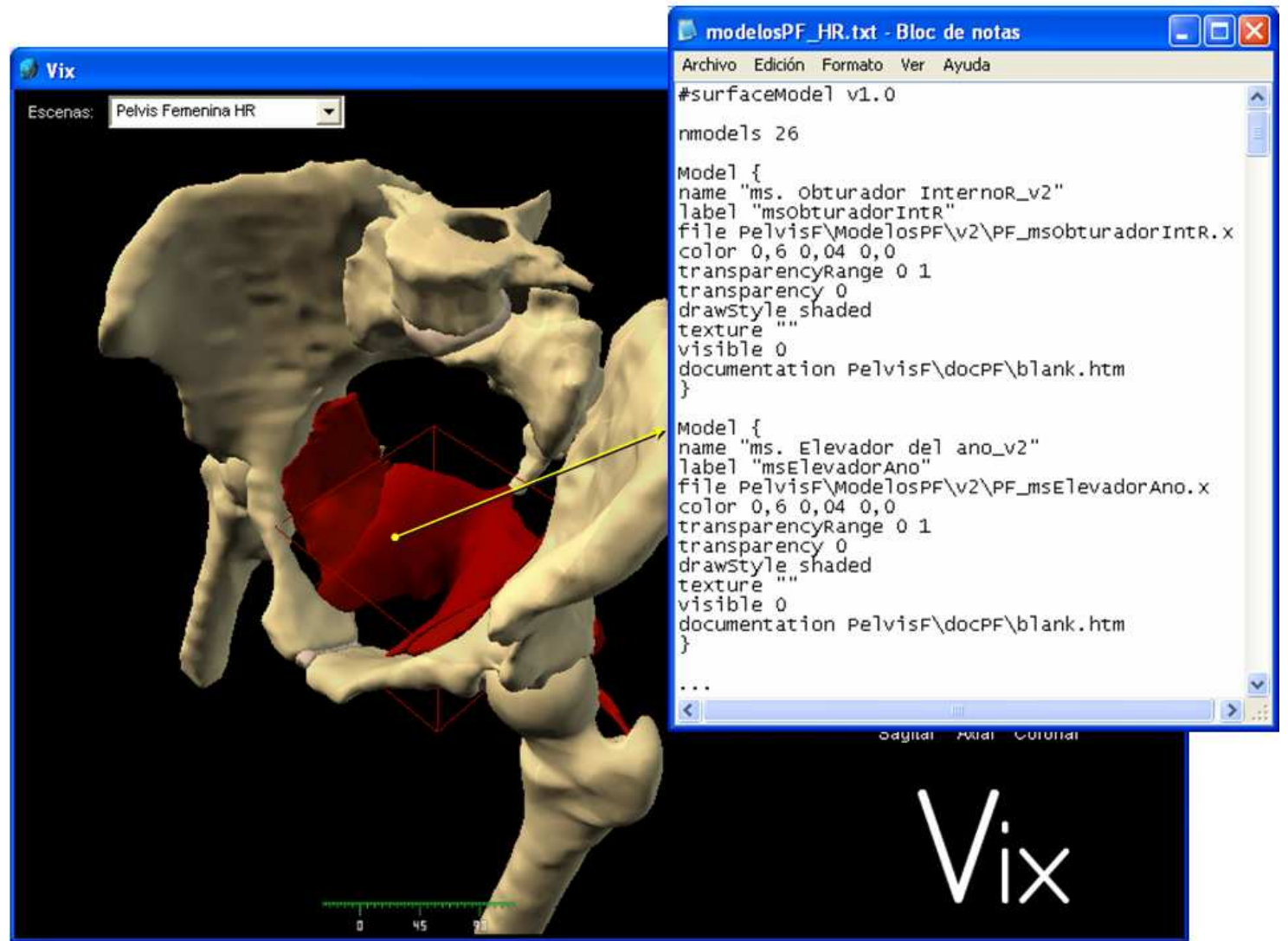

Fig. 8. Ejemplo de fichero de definición de modelos 3D, correspondiente a la escena gráfica mostrada en la Fig. 3.

Brevemente, los principales nodos o tags empleados en los ficheros de definición de modelos tienen las siguientes funciones:

- Model \{\}. Define la creación de un nuevo modelo, cuyas características se especifican entre llaves.

- name. Nombre con el que se aparecerá el modelo en la lista desplegable de selección.

- label. Identificador de modelo, para uso interno.

- file. Fichero en formato DirectX con la geometría del modelo.

- color. Color del modelo, en escala RGB, es decir, con valores de cada componente, rojo ( $\mathrm{R}$-red-), verde ( $\mathrm{G}$-green-) y azul (B -blue-), entre 0 y 1.

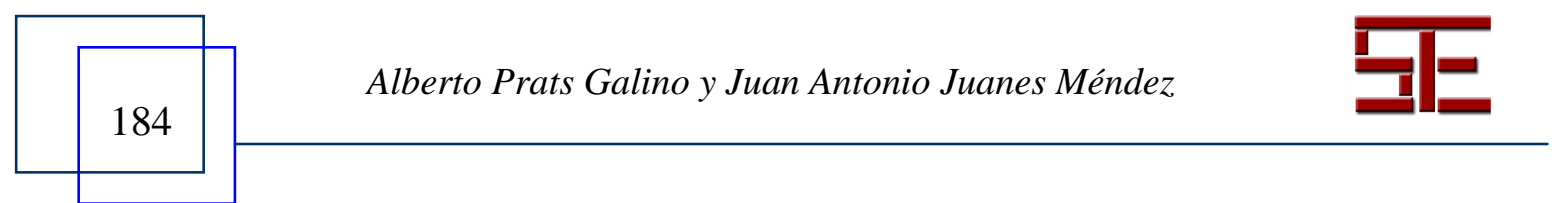




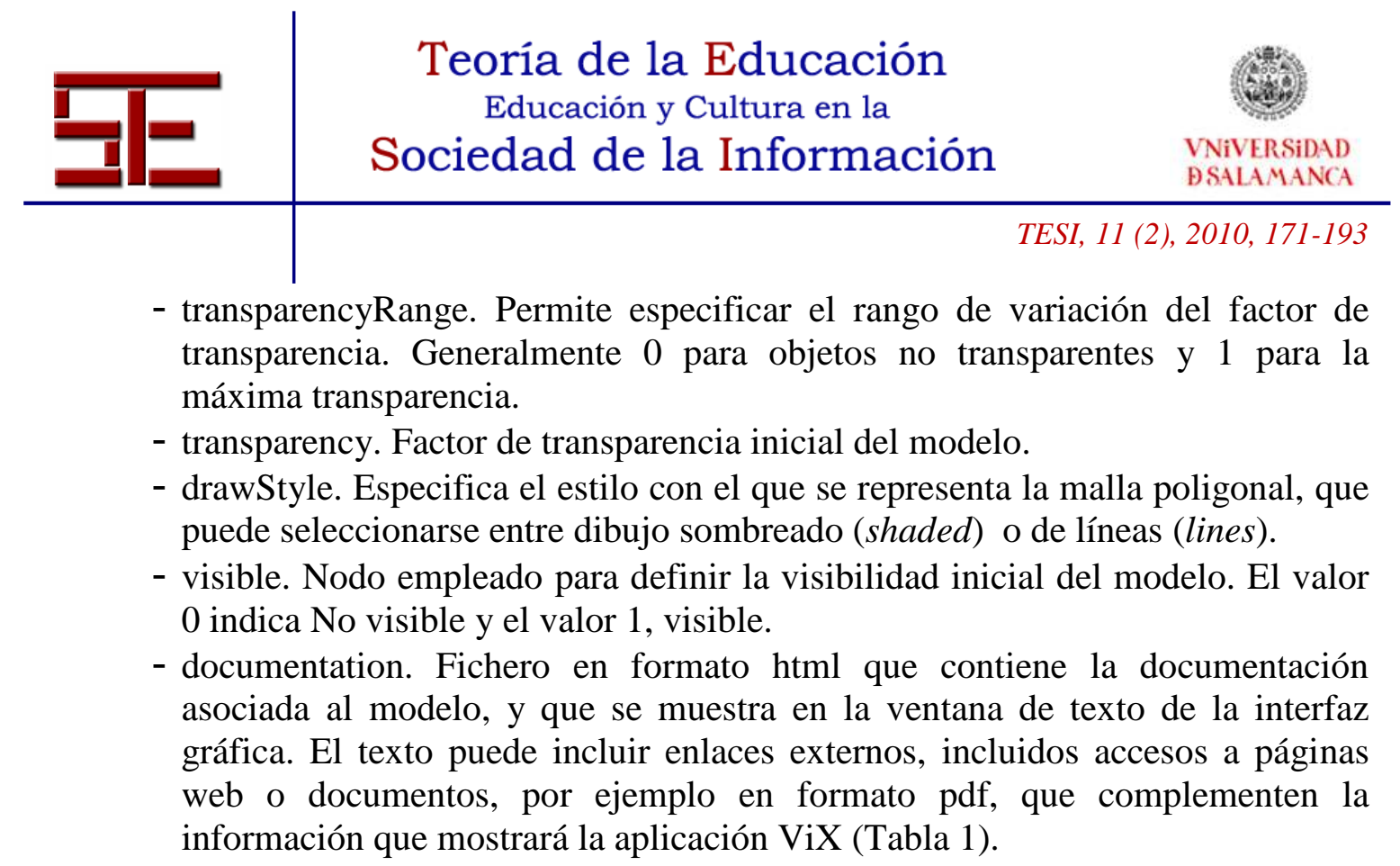

\section{Córtex visual}

Parte de la corteza cerebral localizada en el lóbulo occipital donde finalizan las radiaciones ópticas. Su integridad es necesaria para la visión consciente. Corresponde al área 17 de Brodmann, con un gran desarrollo de la lámina IV(ver Fig. citoarquitectura).

Enlaces relacionados:

- Organización Vías Visuales (animación PowerPoint)

- Esquemas (web)

- $\underline{\text { Caso Clínico (fichero pdf) }}$

Tabla 1: Ejemplo de material documental con una breve descripción anatómica del córtex visual, que incluye 4 tipos de enlace externos a la aplicación ViX: una imagen (Fig.), un documento PowerPoint (Organización Vías Visuales), un documento pdf (Caso Clínico) y una dirección de Internet (Esquemas)

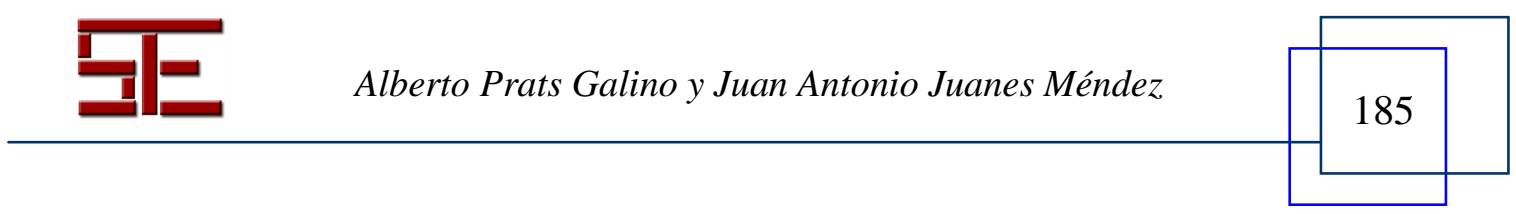




\begin{tabular}{ccc}
$\begin{array}{c}\text { Teoria de la Educación } \\
\text { Educación y Cultura en la } \\
\text { VNiVERSIDAD } \\
\text { BSALAMANCA }\end{array}$ & Sociedad de la Información \\
\hline TESI, $11(2), 2010,170-193$ &
\end{tabular}

\section{4.- Aplicaciones implementadas en ViX}

Debido al diseño abierto de la plataforma ViX, se han podido ir desarrollando sucesivas aplicaciones para el estudio de diferentes regiones anatómicas, sin tener que modificar su código de programación. Señalaremos a continuación las características de las cuatro aplicaciones más relevantes implementadas en este entorno.

\subsection{1.- Cerebro virtual}

Desarrollado a partir de imágenes de criosecciones anatómicas procedentes del Visible Human Project (www.nlm.nih.gov/research/visible/visible_human.html). Incluye asimismo modelos 3D procedentes del proyecto UB-Brain (Juanes y cols., 2003; Prats y Juanes, 2007), de las principales estructuras cerebrales profundas: sistema ventricular, ganglios basales, tálamo, hipocampo, amígdala, cuerpos mamilares y comisuras cerebrales (cuerpo calloso, fórnix y comisura anterior) (Fig. 9). Está siendo empleado en el campo de la neuroanatomía, en estudios tanto de pregrado (Medicina, Psicología, Enfermería, Fisioterapia) como de postgrado (Neurología, Neurorradiología, Psiquiatría).

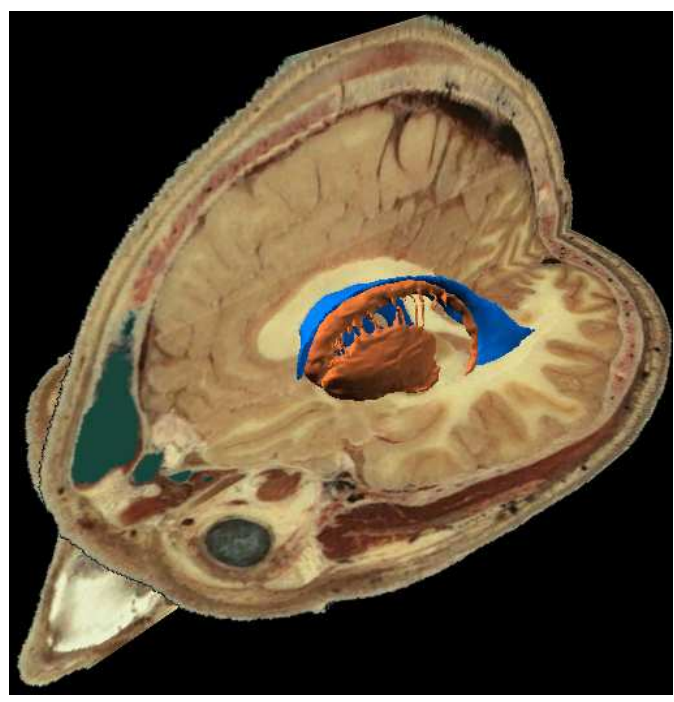

Proyecto: cerebro virtual

\begin{tabular}{|c|c|}
\hline modalidad & secciones anatómicas \\
\hline sec. axiales & $\mathrm{n}=22, \operatorname{dim}=576 \times 768, \mathrm{res}=0.3$ \\
\hline sec. coronales & $\mathrm{n}=13, \operatorname{dim}=576 \times 480$, res $=0.3$ \\
\hline sec. sagitales & $\mathrm{n}=15, \operatorname{dim}=768 \times 480$, res $=0.3$ \\
\hline modelos 3D & 14 \\
\hline aplicación & $\begin{array}{l}\text { neuroanatomía, en pregrado } \\
\text { (Ciencias de la Salud) y postgrado } \\
\text { (Neurología) }\end{array}$ \\
\hline
\end{tabular}

Fig. 9: Características del proyecto "Cerebro virtual” implementado en ViX

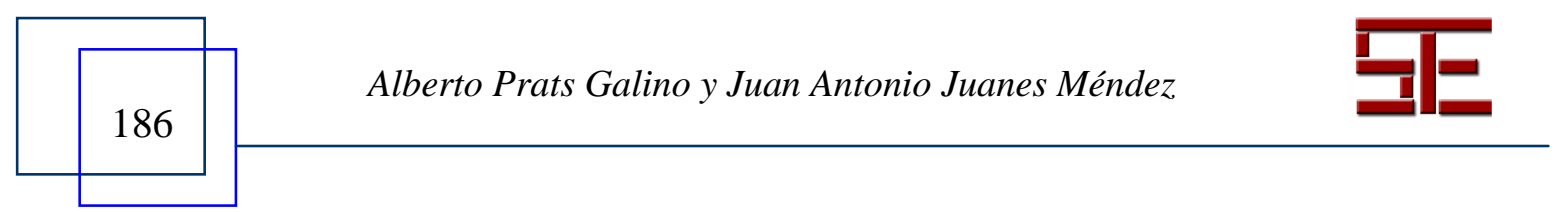




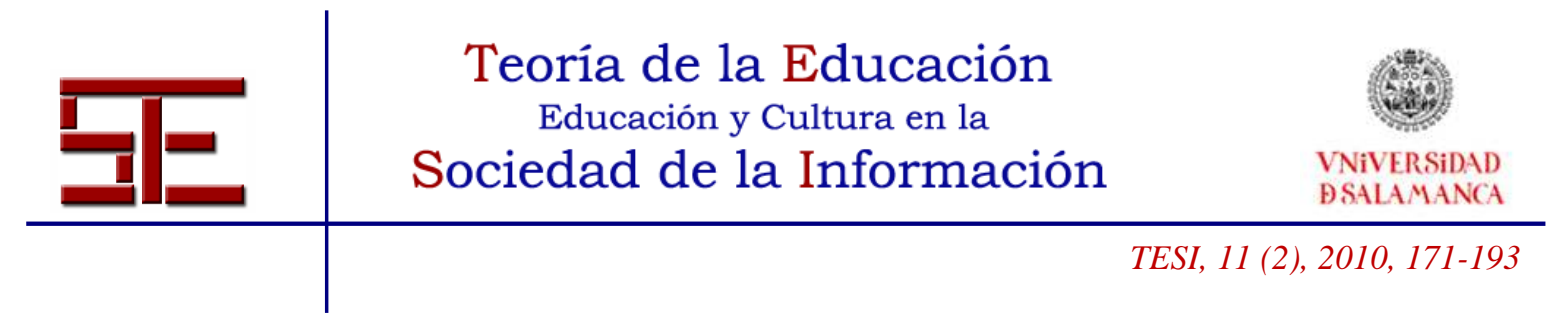

\subsection{2.- Pelvis virtual femenina}

El proyecto de pelvis femenina se ha implementado a partir de tres volúmenes independientes de RM en densidad protónica de la región abdominopélvica, adquiridos en cada una de las orientaciones espaciales, con la finalidad de asegurar una alta resolución de las imágenes, próxima al milímetro. La metodología empleada para su obtención ha sido descrita previamente (Espuña y cols., 2006; Martínez de IbarretaZorita, 2008). La aplicación incluye un total de 26 modelos 3D correspondientes a estructuras óseas, musculares y viscerales del suelo pélvico (Fig. 10). El programa es útil para el estudio de las complejas relaciones topográficas del suelo de la pelvis femenina, habiendo sido empleado en la formación especializada en ginecología y enfermería.

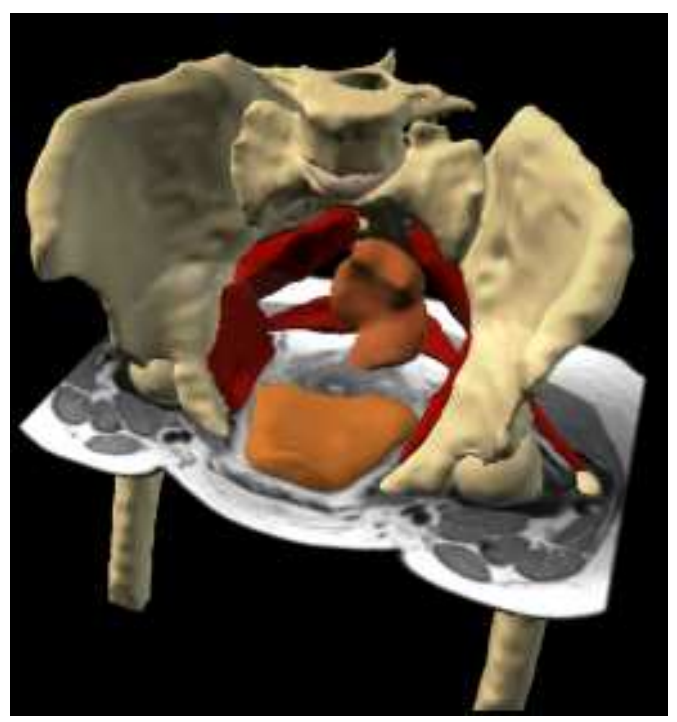

\begin{tabular}{|c|c|}
\hline \multicolumn{2}{|c|}{ Proyecto: pelvis virtual femenina } \\
\hline modalidad & RM, densidad protónica \\
\hline sec. axiales & $\mathrm{n}=18, \operatorname{dim}=300 \times 280, \mathrm{res}=1$ \\
\hline sec. coronales & $\mathrm{n}=11, \operatorname{dim}=300 \times 280, \mathrm{res}=1$ \\
\hline sec. sagitales & $\mathrm{n}=11, \operatorname{dim}=280 \times 280, \mathrm{res}=1$ \\
\hline modelos 3D & 26 \\
\hline aplicación & $\begin{array}{l}\text { anatomía del suelo de la pelvis, en } \\
\text { pregrado (Medicina) y postgrado } \\
\text { (Ginecología, Enfermería) }\end{array}$ \\
\hline
\end{tabular}

Fig. 10: Características del proyecto "Pelvis virtual femenina" implementado en ViX

\subsection{3.- Vías ópticas}

Las vías visuales y del sistema oculomotor se han reconstruido a partir de una RM craneal potenciada en $\mathrm{T} 1$ de vóxels submilimétricos $(0.8 \mathrm{~mm})$. El desarrollo de esta aplicación ha precisado, además, de la obtención de un TC de alta resolución del hueso esfenoides aislado, cuyo ROI ha sido reeditado manualmente tras su corregistro con la RM. Han sido modelizadas todas las estructuras nerviosas que componen las vías visuales, desde el globo ocular hasta el córtex visual primario, y los diferentes componentes neuromusculares del sistema que controla la motilidad ocular (Riesco del

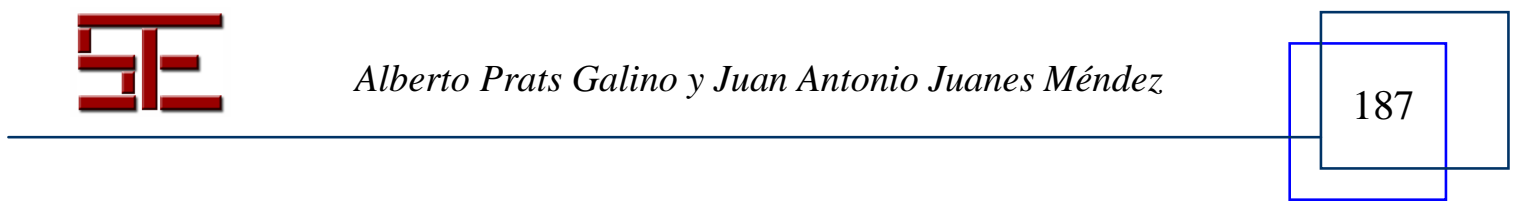




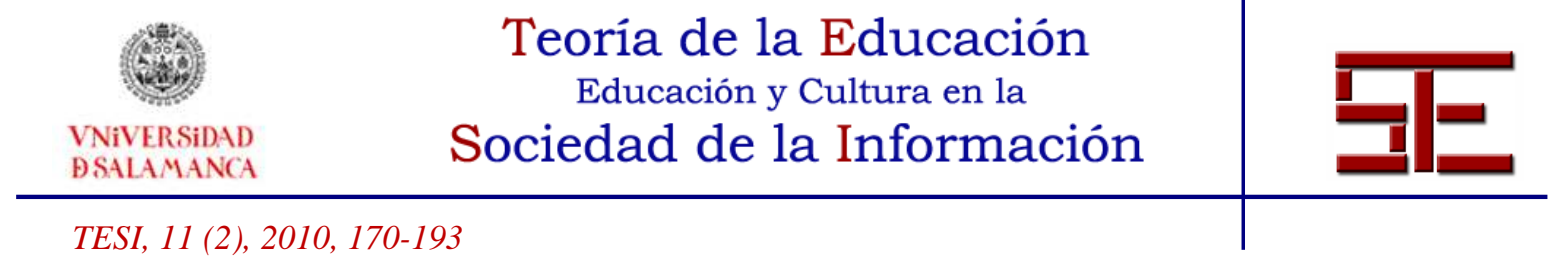

Pino, 2009), de interés en campos relacionados con la Oftalmología y Neurología (Fig. $11)$.

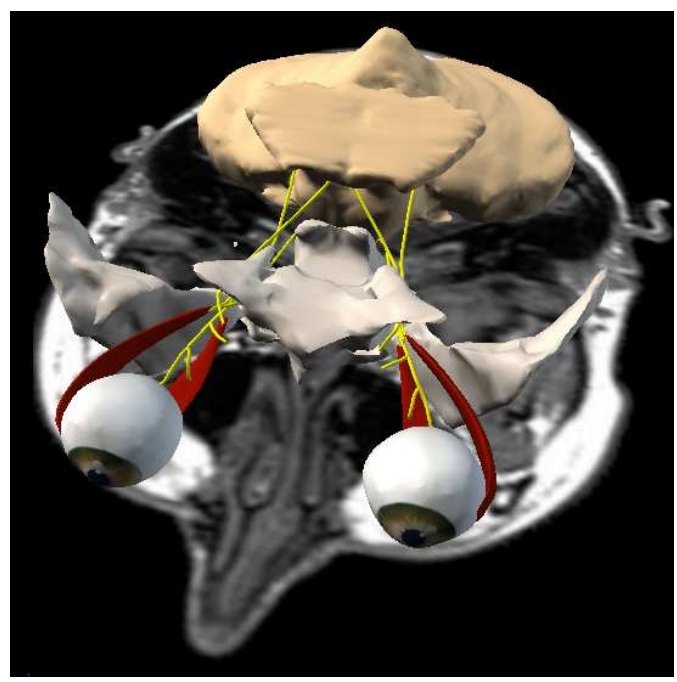

\begin{tabular}{ll}
\hline Proyecto: vías ópticas \\
\hline modalidad & RM, potenciada T1 \\
sec. axiales & $\mathrm{n}=14, \operatorname{dim}=276 \times 276$, res $=0.8$ \\
sec. coronales & $\mathrm{n}=20, \operatorname{dim}=376 \times 200$, res $=0.8$ \\
sec. sagitales & $\mathrm{n}=17, \operatorname{dim}=200 \times 276$, res $=0.8$ \\
modelos 3D & 20 \\
aplicación & $\begin{array}{l}\text { anatomía de las vías ópticas y } \\
\text { sistema oculomotor, en pregrado } \\
\text { (Medicina) y postgrado (Neurología) }\end{array}$
\end{tabular}

Fig. 11: Características del proyecto "Vías ópticas" implementado en ViX

\subsection{4.- Cráneo virtual}

El proyecto de cráneo virtual ha dado lugar a distintas aplicaciones, basadas en la obtención de dos tipos de modelo 3D generados a partir de una misma TC craneal de alta resolución $(0.4 \mathrm{~mm})$. El primer tipo consiste en un cráneo completo, con y sin bóveda, que permite el estudio de las fosas y detalles anatómicos tanto de la superficie endocraneal (fosas anterior, media y posterior) como de la exocraneal (fosas orbitaria, nasal, infratemporal, pterigomaxilar). El segundo tipo corresponde a un modelo de macizo craneofacial, para el estudio más detallado de esta región, en el que pueden incluirse modelos individuales de cada diente, de especial interés en Odontología. Un ejemplo de aplicación del modelo maxilofacial utilizado para explicar diferentes vías anestésicas se muestra en la Fig. 12.

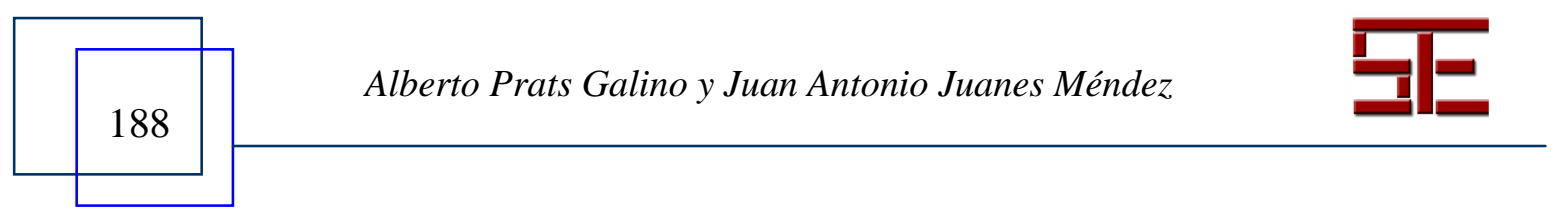



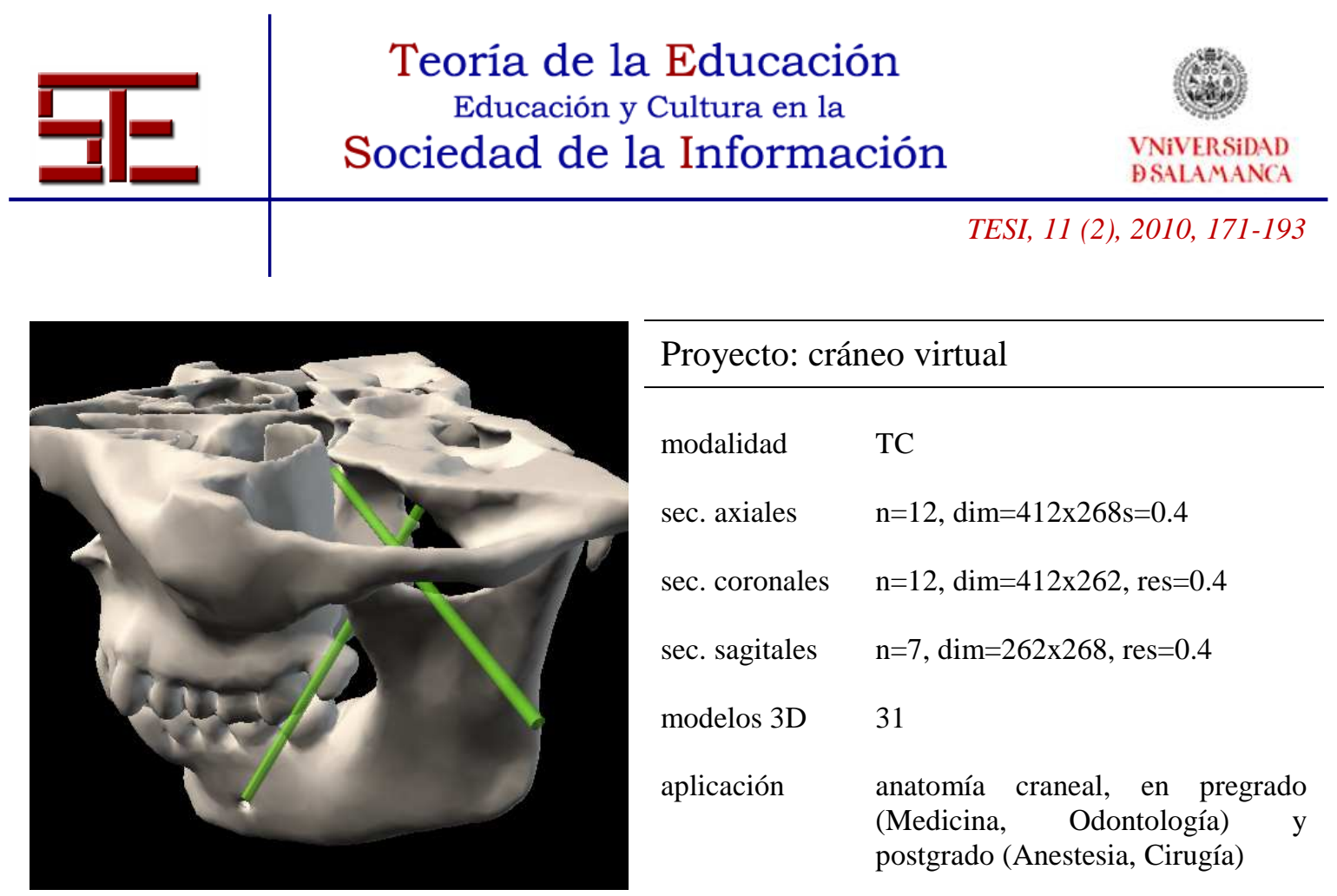

\begin{tabular}{|c|c|}
\hline \multicolumn{2}{|c|}{ Proyecto: cráneo virtual } \\
\hline modalidad & $\mathrm{TC}$ \\
\hline sec. axiales & $n=12, \operatorname{dim}=412 \times 268 s=0.4$ \\
\hline sec. coronales & $\mathrm{n}=12, \operatorname{dim}=412 \times 262, \mathrm{res}=0.4$ \\
\hline sec. sagitales & $\mathrm{n}=7, \operatorname{dim}=262 \times 268$, res $=0.4$ \\
\hline modelos 3D & 31 \\
\hline aplicación & $\begin{array}{l}\text { anatomía craneal, en pregrado } \\
\text { (Medicina, Odontología) y } \\
\text { postgrado (Anestesia, Cirugía) }\end{array}$ \\
\hline
\end{tabular}

Fig. 12: Características del proyecto "Cráneo virtual” implementado en ViX

\section{5.- DISCUSIÓN Y CONCLUSIONES}

En los últimos años, los avances informáticos y de las técnicas de comunicación se han incorporado progresivamente al terreno formativo en las Ciencias de la Salud con el objetivo de elevar la eficiencia de los procesos de aprendizaje. Esta paulatina introducción de diferentes tecnologías en la enseñanza de la Medicina y otras disciplinas afines se ha realizado en función de las características y requerimientos de los distintos procesos educativos en cada centro universitario. Parte de los cambios tecnológicos han afectado al hardware, cada vez con mayores prestaciones gráficas y capacidades de cálculo intensivo, pero también a los novedosos desarrollos informáticos orientados a la docencia tanto presencial como a distancia , que forman parte de la metodología docente empleada de forma habitual por los profesores universitarios.

Dichos avances han sido especialmente significativos en los sistemas de representación gráfica empleados en diferentes ámbitos de Ciencias de la Salud, en los cuales la comunicación y transferencia de conocimientos mediante imágenes biomédicas, y específicamente las relativas al estudio de la anatomía humana, han adquirido una gran relevancia.

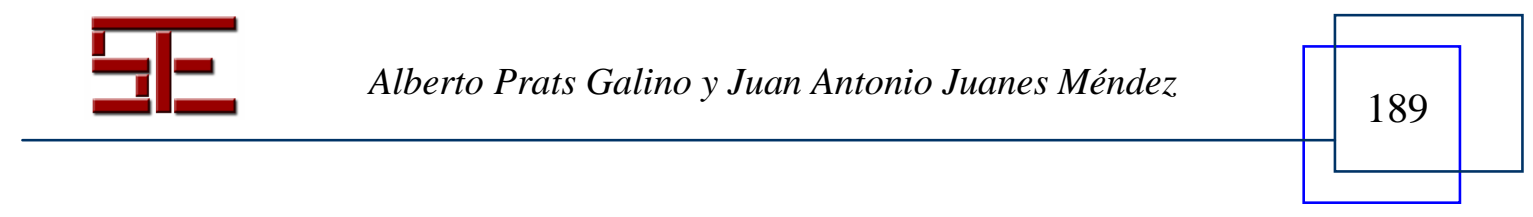




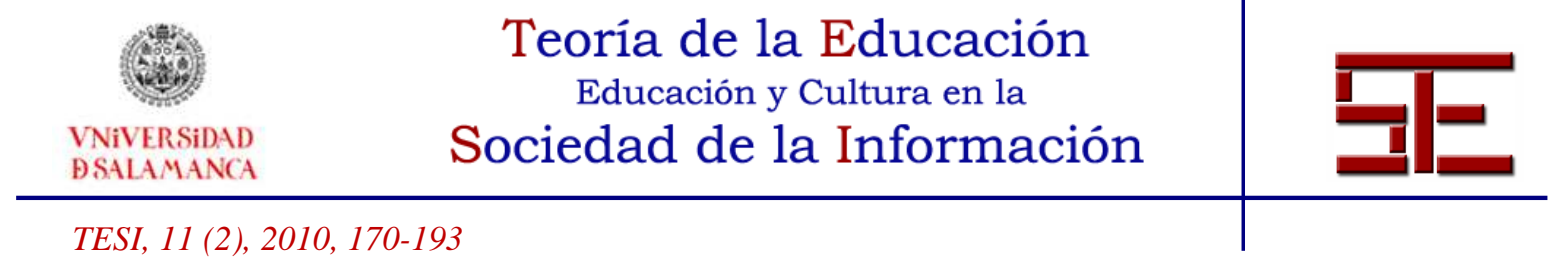

Desde el punto de vista de su evolución cronológica, los sistemas utilizados para representar gráficamente las estructuras anatómicas pueden ser clasificados en tres generaciones principales. La primera incluye los materiales impresos, entre los que se encuentran tratados generales de anatomía (Netter, 2007; Schunke y cols., 2008; Rohen y cols., 2009), de anatomía topográfica o de aparatos y sistemas específicos (Llusá y cols, 2004) y de anatomía con orientación clínica (Cappabianca y cols., 2009). La segunda generación aparece con el uso de formatos multimedia, típicamente imágenes digitales 2D (Netter, 2002, A.D.A.M., 2003). La tercera generación se refiere a las aplicaciones informáticas con vistas 3D y modelos generados por ordenador (Höhne, 2009; Kockro y Hwang, 2009; Prats y Juanes, 2007; PRIMAL, 2009; Talos y cols., 2008). Estas últimas permiten, a su vez, generar y exportar imágenes de primera y segunda generación.

La presentación de información gráfica mediante soporte impreso es estática, no ampliable, y no transferible. Normalmente sólo algunas estructuras están identificadas mediante marcadores o etiquetas, siendo generalmente el número de vistas muy limitado, lo cual dificulta la comprensión de las relaciones espaciales. La segunda generación supera parcialmente estas limitaciones, pero sólo muestran información en dos dimensiones. El empleo de plataformas web por Internet (Peterson y cols., 2009; Web: Gray's Anatomy; Web: Homo sapiens dissecatus; Web: The Multi-Dimensional Human Embryo) y de formatos electrónicos estandarizados han supuesto un paso decisivo para la difusión de este tipo de documentos. Una aplicación de tercera generación, entre las que se incluye la plataforma descrita, permite al usuario modificar interactivamente el punto de vista mediante la manipulación de modelos y la aplicación de planos de sección en volúmenes de datos específicos (por ej., de tipo radiológico) procedentes de sujetos normales o de pacientes.

Por este motivo, el uso de aplicaciones de inmersión de tercera generación en entornos de simulación se está implantando de forma habitual como sistemas de educación en todas las especialidades quirúrgicas (Apuzzo, 2009; Wiet y cols., 2002). Así, los desarrollos informáticos basados en la simulación constituyen un poderoso método tecnológico que enseña al usuario aspectos concretos que se encontrará en su actividad profesional, imitándolos o replicándolos.

Evidentemente, la simulación biomédica no está exenta de limitaciones, pues suele implicar una simplificación de la realidad, al omitir o modificar detalles. Sin embargo, esta simplificación puede ayudar al estudiante a construir un modelo mental útil del sistema representado, permitiendo además la adquisición de habilidades que serán desarrolladas de manera similar a la empleada en situaciones reales.

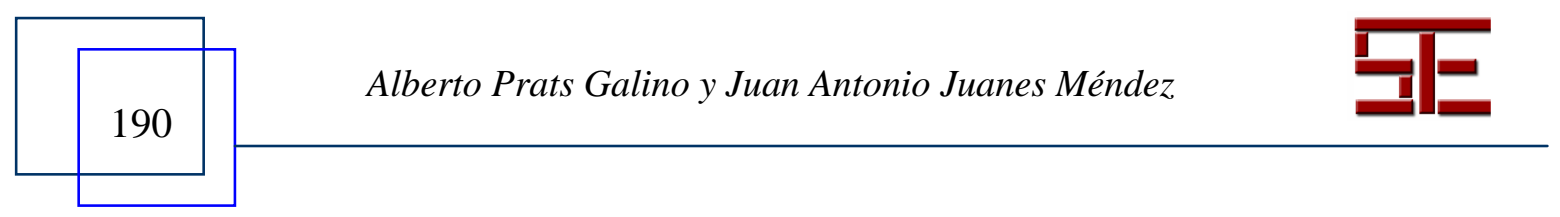




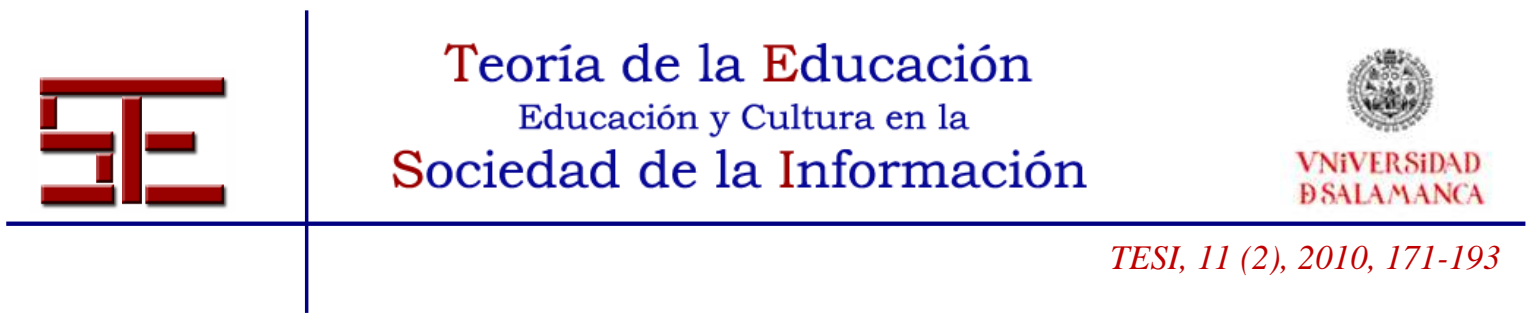

Los programas informáticos de carácter educativo deben tener como objetivo orientar el aprendizaje de los estudiantes, promoviendo actuaciones de los mismos encaminadas a facilitar la consecución de objetivos educativos determinados. En este sentido, la plataforma ViX, por su naturaleza abierta, supone un paso más en el desarrollo de diferentes aplicaciones biomédicas en un entorno 3D, adaptadas a objetivos específicos.

Por último, destacar que este tipo de tecnología representa una poderosa y versátil herramienta docente que transforma a los usuarios (estudiantes), de receptores pasivos de la información, en participantes activos, facilitando el despliegue de recursos cognitivos de gran importancia en los procesos de enseñanza-aprendizaje.

\section{6.- BIBLIOGRAFÍA}

A.D.A.M. (2003): Interactive Anatomy 3.06 Students Edition, A.D.A.M., Sofware Inc. ANECA (2005): Libro Blanco Titulación Medicina. Diseño de Planes de Estudio y Título de Grado. Programas de Convergencia Europea.

Apuzzo, M.L. (2009). Virtual neurosurgery: forceps, scissors, and suction meet the microprocessor, rocket science, and nuclear physics. Neurosurgery 64: 785.

Cappabianca, P., Califano, L E Iaconetta, G. (2009). Cranial, Craniofacial and Skull Base Surgery. New York. Springer Verlag.

Carmichael, S.W. Y Pawlin, W. (2000). Animated Power Point as a tool to teach anatomy. Anat. Rec, 261:83-88.

Elizondo-Omaña, R.E., Morales, J.A., Lopez, S.; Leon, I.; Patiño, R. Y Cavazos, F. (2004). Tradicional teaching supported by computer assited learning for macroscopic anatomy. Anat Rec (New Anat), 278B: 18-22.

Espuña, M., Juanes, J.A., Prats, A., Tomas, X., Carera, A., Gómez, J.J. E Ilesias, X. (2006). Modelización virtual de la pelvis femenina a partir de imágenes de resonancia magnética. Suelo Pélvico 2: 85-90.

Höhne K.H. (2009). VOXEL-MAN 3D-Navigator: Brain and Skull: Regional, Functional, and Radiological Anatomy. Springer.

Juanes, J.A., Prats, A., Lagándara, M.L., Riesco, J.M. (2003). Application of the "Visible Human Project" in the field of anatomy: a review. Eur. J. Anat. 7: 147-59

Kockro, R.A. Y Hwang, P.Y. (2009). Virtual temporal bone: an interactive 3dimensional learning aid for cranial base surgery. Neurosurgery 64: 216-229; discussion 229-30.

Llusá, M., Merí, A. Y Ruano, D. (2004). Manual y Atlas Fotográfico de Anatomía del Aparato Locomotor. Madrid. Editorial Médica Panamericana.

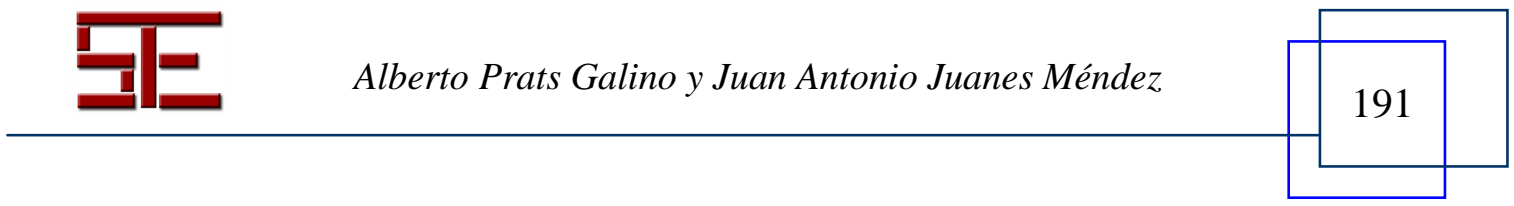




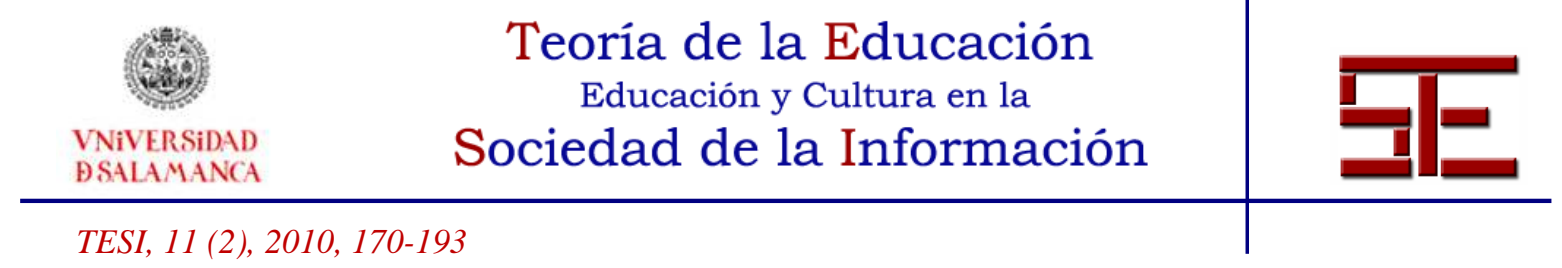

Martínez De Ibarreta-Zorita, J. (2008). Modelización virtual de la pelvis femenina a partir de imágenes de resonancia magnética. Tesis doctoral. Universidad de Salamanca.

Netter, F.H. (2002). Interative Atlas of Human Anatomy (v 2.0). Novartis.

Netter, F.H. (2007). Atlas de Anatomía Humana (4 ${ }^{\mathrm{a}}$ ed). Barcelona, Elsevier Doyma.

Peterson, H., Sinkvist, D., Wang, C. Y Smedby, O. (2009). Web-based interactive 3D visualization as a tool for improved anatomy learning. Anat Sci Educ 2: 61-68

Prats, A., Juanes, J.A. (2007). UB-Brain v2.0. Barcelona, Publicaciones i Edicions. Universitat de Barcelona.

Primal (2009): 3D Human Anatomy: Regional Edition. PrimalPictures.com

Riesgo Del Pino, A.M. (2009). Entorno virtual de visualización 3D de la vía óptica y sistema oculomotor, a partir de secciones seriadas de resonancia magnética. Tesis doctoral. Universidad de Salamanca.

Rohen, J.W.; Lütien-Drecoll, E. Y Yocochi, C. (2009). Atlas de Anatomía Humana. Barcelona. Elsevier.

Schünke, M., Schulte, E Y Schumacher, U. (2008). PROMETHEUS, Texto y Atlas de Anatomía. Madrid. Panamericana.

Talos, I., Jakab, M., Kikinis, R. Y Shenton, M. (2008). SPL-PNL Brain Atlas. Surgical Planning Laboratory, Harvard Medical School, Boston.

WEB: Gray's Anatomy. http://www.theodora.com/anatomy/

WEB: Homo sapiens dissecatus.

http://www.uni-mainz.de/FB/Medizin/Anatomie/workshop/VH/male/axial/axial.html

WEB: The Multi-Dimensional Human Embryo. http://embryo.soad.umich.edu/

Wiet, G.J., Stredney, D., Sessanna, D., Bryan, J.A., Welling, D.B. Y Schmalbrock, P. (2002). Virtual temporal bone dissection: an interactive surgical simulator. Otolaryngol Head Neck Surg 127: 79-83

\section{AGRADECIMIENTOS}

A la Empresa Desarrollos Informáticos Abadía, de Madrid, por su participación en el diseño y programación de la plataforma ViX. A Olga Fuentes, del Laboratorio de NeuroAnatomía Quirúrgica (LSNA) de la Facultad de Medicina, Universidad de Barcelona (UB), por su inestimable colaboración en la obtención de modelos 3D. Las diferentes aplicaciones presentadas en este trabajo han sido parcialmente financiadas por el Gabinet d'Avaluació i Innovació Universitària (GAIU) de la UB (Proyectos 9/IV/MM-Cd/05/PRAT, 10/IV/MM-OI/28/PRAT, 2003PID-UB/26, 2005PID-UB/22) у Departament d'Universitats, Recerca i Societat de la Informació, Generalitat de Catalunya (Proyectos 233MQD y 2005MQD 00149).

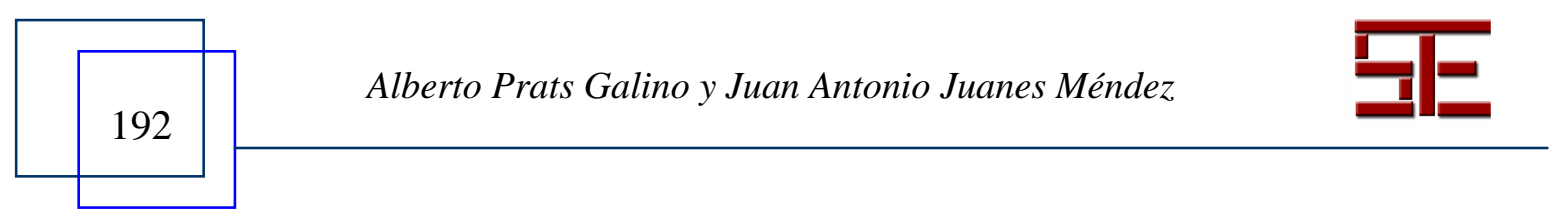




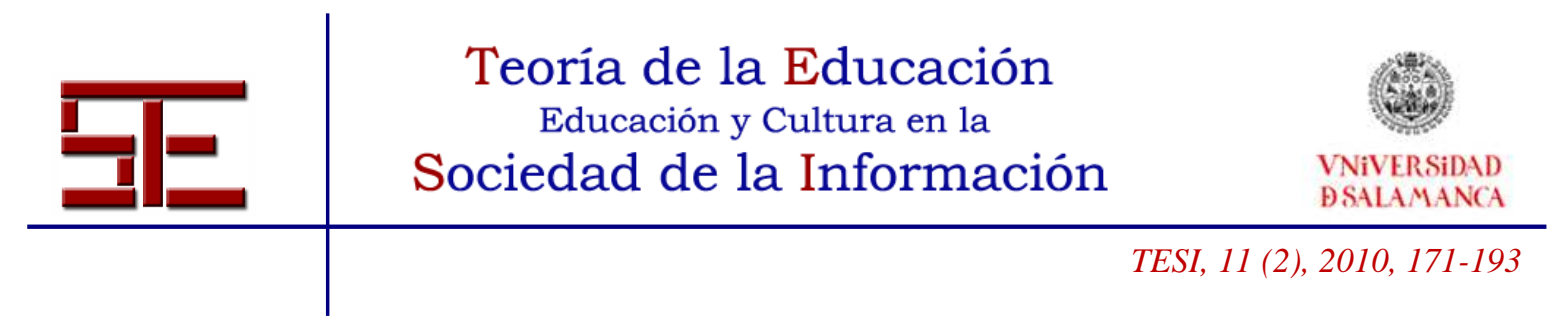

Para citar el presente artículo puede utilizar la siguiente referencia:

Prats Galino, A. (2010): VIX: una aplicación informática abierta para la visualización y estudio interactivo de la anatomía en 3D, en Juanes Méndez, J.A. (Coord.) Avances tecnológicos digitales en metodologías de innovación docente en el campo de las Ciencias de la Salud en España. Revista Teoría de la Educación: Educación y Cultura en la Sociedad de la Información. Vol. 11, $\mathrm{n}^{\mathrm{o}}$ 2. Universidad de Salamanca, pp. 171-193 [Fecha de consulta: $\mathrm{dd} / \mathrm{mm} / \mathrm{aaaa}]$.

http://campus.usal.es/ revistas_trabajo/index.php/revistatesi/article/view/7076/7109

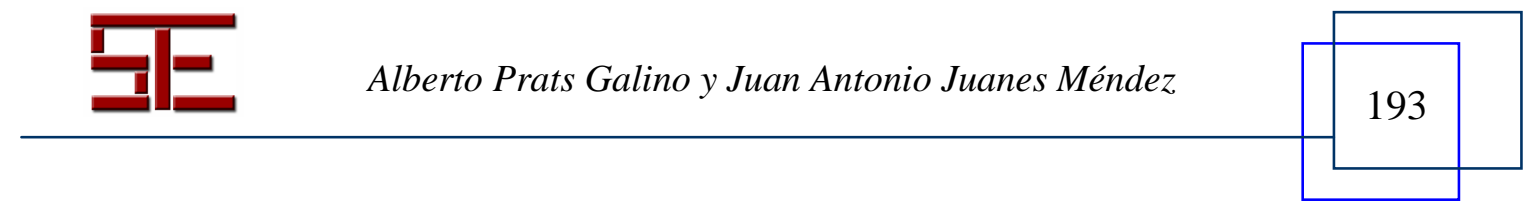

